Portland State University

PDXScholar

Spring 2011

Investigation and Evaluation of Current and

Emerging Whole-Water Sampling Technologies for

U.S. Geological Survey National Water Quality

\title{
Assessment Program
}

Keith D. Gareau

Portland State University

Follow this and additional works at: https://pdxscholar.library.pdx.edu/mem_gradprojects

Part of the Environmental Monitoring Commons, and the Water Resource Management Commons Let us know how access to this document benefits you.

\section{Recommended Citation}

Gareau, Keith D., "Investigation and Evaluation of Current and Emerging Whole-Water Sampling Technologies for U.S. Geological Survey National Water Quality Assessment Program" (2011). Master of Environmental Management Project Reports. 20.

https://pdxscholar.library.pdx.edu/mem_gradprojects/20

https://doi.org/10.15760/mem.20

This Project is brought to you for free and open access. It has been accepted for inclusion in Master of Environmental Management Project Reports by an authorized administrator of PDXScholar. Please contact us if we can make this document more accessible: pdxscholar@pdx.edu. 
Investigation and Evaluation of Current and Emerging Whole-Water Sampling Technologies For U.S. Geological Survey National Water Quality Assessment Program

\author{
Keith D. Gareau
}

Master of Environmental Management Project Department of Environmental Science and Management Portland State University

June 2011 
Table of Contents

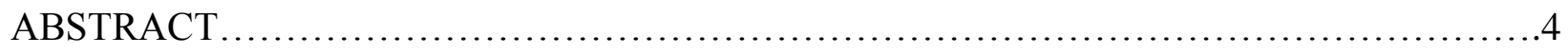

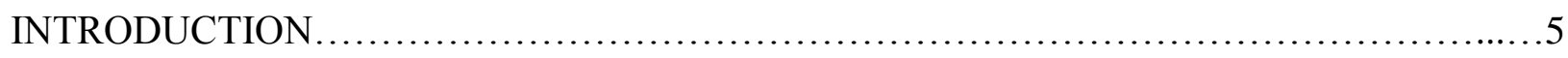

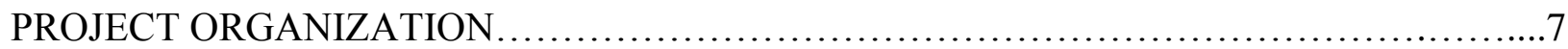

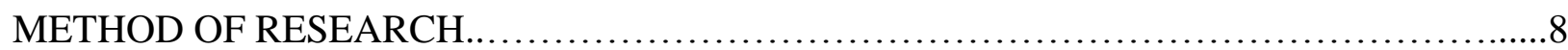

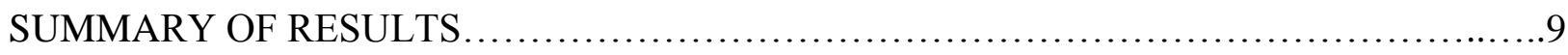

CURRENT LOTIC SAMPLERS ........................................... 10

PORTALBE AUTONOMOUS WHOLE-WATER SAMPLERS ........................14

CURRENT AUTONOMOUS SUBMERGIBLE WHOLE-WATER SAMPLERS.......17

EMERGING AUTONOMOUS SUBMERGIBLE WHOLE-WATER SAMPLERS.......21

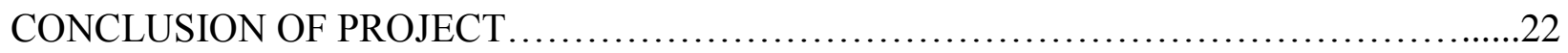

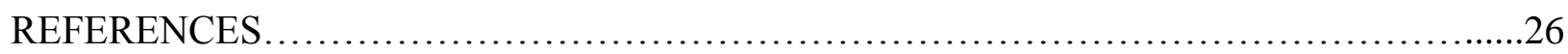

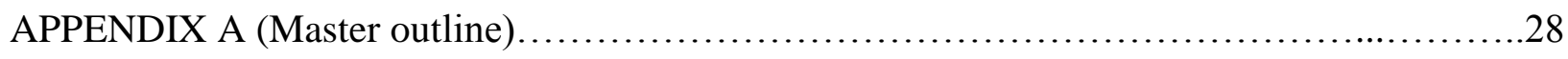

APPENDIX B (Lotic water samplers) ....................................................

APPENDIX C (Portable autonomous whole-water samplers) ............................42

APPENDIX D (Autonomous submergible whole-water samplers) $\ldots \ldots \ldots \ldots \ldots \ldots \ldots \ldots \ldots \ldots \ldots . \ldots$ 


\begin{abstract}
An investigation was conducted into current and emerging surface water sampling technologies. These technologies were compared and recommendations given to the United States Geological Survey (USGS) for adoption by the National Water Quality Assessment (NAWQA) Program. The goal is to reduce labor costs and increase information content. This paper examines lotic system samplers, portable autonomous whole-water samplers, and autonomous submergible whole-water samplers. When investigating whole-water sampling technology, it was imperative to take into consideration what chemical classifications can be sampled for by each respected technology. Chemical classifications considered are: emerging contaminants, major ions, nutrients, polychlorinated biphenyls, pesticides, volatile and semi-volatile organic compounds, and trace elements. The result of this project shows that USGS is currently using the best technology available for lotic systems. For portable autonomous whole-water samplers it is recommended that USGS incorporate certain brands and models to reduce cost and improve data collection for their sampling events. Autonomous submergible whole-water samplers are primarily advertised for oceanic research; however, if deployed in fresh water systems, USGS can reduce labor cost and increase data collection. In terms of emerging technology, it has been recommended to USGS to consider recent patents.
\end{abstract}

Keywords: water quality sampling, portable autonomous whole-water sampling, autonomous submergible whole-water sampling 
Investigation and Evaluation of Current and Emerging Whole-Water Sampling Technologies for U.S. Geological Survey National Water Quality Assessment Program

\section{Introduction}

With ever increasing requirements for water quality protection and ever decreasing federal budgets, it is imperative to invest each agency dollar wisely. This is particularly true in the area of water quality sampling, where the cost of manual collection is high, but investing in the wrong technology to mechanically collect samples can bear an even higher cost. To determine the best technology to mechanically collect water quality samples, the United States Geological Survey (USGS) recently funded a project to compare and analyze current and emerging sampling methods for surface waters for implementation in the National Water Quality Assessment (NAWQA) Program for the USGS.

The USGS is located within the Department of Interior and has the goal to collect scientific information on the health of our nation's ecosystems and environment along with providing access to data, publications, and maps of projects and events related to the scientific information collected (Cech, 2003; USGS, 2011). A subdivision of USGS is the NAWQA Program, founded in 1991, which assesses the quality of the nation's streams and groundwater, determines how water quality changes over time, and how natural and anthropogenic events change water quality (USGS, 2010).

To interpret water quality data accurately, the USGS has created the National Field Manual for the Collection of Water-Quality Data which provides standard methods and procedures. The field manual is used by water quality personnel in government and private industry. Even though standard methods and procedures have been developed by USGS for the analysis of water quality data, standard methods have inherent drawbacks. According to Lepom et al. (2009), standard methods take a long time to develop and implement, and do not always represent the current state of the art technology and methodologies and offer little flexibility to the user to choose from different sampling options. Therefore, it is essential to evaluate the current sampling methods and to report on emergent technology to provide the scientific community with the most effective, accurate, and precise data.

The USGS wanted an assessment of current and emerging sampling methods, which involved an in-depth literary review of technologies used in surface water including: time- 
integrating passive samplers, volume-integrating whole-water samplers, remote sensing, and sensors to measure a variety of environmental contaminants. The volume-integrating wholewater sampler discussion was broken into two research sections due to anticipated large volumes of information on this specific sampling methodology: lotic whole-water samplers and lentic whole-water samplers. Lotic systems are unidirectional flowing water systems imposed by gravity, such as streams and rivers, while lentic systems involve standing water systems such as ponds and lakes (Kalff, 2002).

NAWQA has also developed a list of 436 unregulated contaminants that are considered to be a potential concern to human health (HBSL, 2008). The 436 contaminants fall under the chemical classifications of: emerging organic and inorganic contaminant, major ions, nutrients, polychlorinated biphenyls (PCB), pesticides, volatile organic compounds/semi-volatile organic compounds (VOC/SVOC), and trace elements (HBSL, 2008). The concerns for these contaminants are that they are unregulated and are becoming detected in the environment (HBSL, 2008). Not all the compounds on the list are considered to be involved in potential human exposure pathways, however, if in found in drinking water, ingestion is most certain. It is the NAWQA programs obligation to monitor and understand what is happening to these contaminants in the environment.

When investigating whole-water sampling technology, it was imperative to take into consideration what chemical classifications can be sampled for by each respected technology. The wrong construction materials used for sampling can cause contamination of a sample, resulting in inefficient data collection. To measure organics, VOC/SVOC, pesticides, PCB, and even pharmaceuticals, materials in contact with the sample have to be made out of fluorocarbon polymers (Teflon), stainless steel, or glass (Wilde, et al., 2004). If the wrong sampling materials are used to sample, the chemical properties of the contaminant will undergo chemical reactions with the sampling materials resulting in a contaminated sample. To measure either inorganics, metals, major ions, or trace elements, polypropylene materials have to be used for the components that come in contact with the sample to prevent contamination (Wilde, et al., 2004). Nutrients, such as nitrate, ammonia, and phosphorus can be sampled with polypropylene, Teflon, stainless steel, or glass materials.

Information found on specific current and emerging technologies was reported describing the background and theory of the sampling method, what chemical classifications can be 
sampled by the technology, a comparison of the specific technologies, followed by recommendations as to what technologies should be adopted by USGS. The USGS will then review the contents of this project and make executive management decisions as to how their organization can improve surface water sampling in ways that reduce labor and increase information content gathered. It was also imperative to incorporate the technologies currently in use by USGS as USGS needs to know what emerging technology can replace current less efficient methods. The information from this project will also provide the basis to construct and deploy at least one emerging identified technology for a field sampling study, along with a journal article based on results from the field study.

The community partner involved in this project was John S. Zogorski of USGS working in conjunction with Portland State University (PSU) Professor of Civil \& Environmental Engineering and Chemistry, Dr. James F. Pankow. The USGS under the NAWQA Program granted Dr. James F. Pankow the responsibility of evaluating current and emerging sampling technologies used for surface waters. Dr. Pankow assembled a team of six researchers to complete the task. Team members consisted of five others: Senior Research Associate Lorne Isabelle of PSU Maseeh College of Engineering \& Computer Science, Senior Research Associate Wentai Luo of PSU Maseeh College of Civil \& Environmental Engineering Engineering \& Computer Science, PSU Graduate Research Assistant Nathan Hersey, PSU Graduate Research Assistant Philip Micha, and William Asher of USGS.

\section{Project Organization}

Each of the researchers chosen by Dr. Pankow was given surface water sampling methods to report on, both current and emerging. As mentioned above, the sampling methods were broken down based on technology: time-integrating passive samplers, volume-integrating whole-water samplers, remote sensing, and sensors. The volume-integrating whole-water sampler research was broken into two groups, lotic system whole-water samplers and lentic whole-water samplers. All of the researchers were to report their investigation on the background and theory of each assigned sampling method, detailed background and theory for each specific technology found, comparisons of specific technologies involving data quality advantages and issues, general cost considerations, and advantages and disadvantages of each specific technology for both current and emerging technologies. 
Dr. Pankow and Lorne Isabelle supervised the research, Wentai Luo was assigned to sensors, Nathan Hersey was given passive sampling, William Asher was assigned to remote sensing, and Philip Micha was given lentic system whole-water sampling. This research investigated and reported information on current and emerging whole-water sampling technologies for lotic systems.

This research team attended weekly meetings where project goals, deadlines, and research progress was discussed in a group setting. The project was initiated the first week of January 2011 and is currently still in progress. The first week involved determining how to break down the overall project and assigning investigation sections on sampling method technology to various individuals. A master outline was created for all research members to follow to simplify formatting and organization of the final product (Appendix A). The researchers were then given three months to produce their findings on current and emerging sample technologies following the master outline. As of April 11, 2011 all the findings on current and emerging technology for each sampling method have been submitted to Dr. James F. Pankow and Lorne Isabelle for review.

\section{Method of Research}

To find information and make assessments of current and emerging sampling technologies for lotic systems required finding and comparing information found in USGS field manuals, water sampling technology manufacturing company websites, journal articles, and water council summits webpages. Patents were also explored. Chapters A2 and A4 of the USGS National Field Manual for the Collection of Water-Quality Data provided information as to what sampling methods are currently being used by USGS specific to lotic systems. This effort provided key words to begin an exhaustive literary search related on whole-water sampling in databases such as Web of Science, Scifinder, and Compendex, to find journal articles related to current or emerging lotic system sample methods and technologies. Examples of used key words involved: whole-water samplers, autonomous water samplers, lotic water samplers, and water quality sampling.

Additionally, a review of printed water quality journals, such as Water Science \& Technology, Water, Air, \& Soil Pollution, American Water Works Association, Water Environment \& Technology, Water Research, Journal of Contaminant Hydrology, and Water 
Environment Research, was completed taking note of the company names advertising water samplers, as it was thought these companies would be on the forefront of new sampling technologies. An online search of each company advertised was then conducted evaluating the whole-water sampling technologies.

A comprehensive search for companies who participated in past National Water Quality Monitoring Council Summits was also piloted. Looking at the National Water Quality Monitoring Council Summit webpage led to many companies who manufacture water quality sampling technology. Finally, a search on Google Patents, using similar key words as the literary search, provided results on emerging whole-water sampling technology.

To understand what chemical classifications NAWQA was interested in, various USGS webpages were researched, especially the USGS Health-Based Screening Level homepage which consist of the 436 unregulated contaminants of interest to NAWQA. The chemical classifications are: emerging organic and inorganic contaminant, major ions, nutrients, polychlorinated biphenyl (PCB), pesticides, volatile organic compounds/semi-volatile organic compounds (VOC/SVOC), and trace elements (HBSL, 2008)

\section{Summary of Results}

Originally, this part of the project was to solely evaluate lotic samplers, however, after an intense literature review, it was discovered that a strong crossover between lotic and lentic samplers existed, excluding one technology, the depth-integrated isokinetic sampler as used by USGS, mentioned below. For this reason, the project was expanded to evaluate autonomous whole-water samplers. This technology type was broken into two discussion sections: portable autonomous whole-water samplers and autonomous submergible whole-water samplers. Autonomous whole-water samplers, also known as automatic samplers, come in a variety of shapes and sizes meeting the demands for various water quality analyses. The basic idea of an automatic sampler is to collect a representative whole-water sample automatically at pre-set intervals from a body of water unattended by personnel for later water quality analysis in the laboratory.

The following sections are the results of the research involving components of the investigation on current and emerging technology, comparisons of specific technology, and recommendations as to what technology should be adopted by USGS for whole-water sampling. 
The technology was broken into three categories: lotic water samplers, portable autonomous whole-water samplers, and autonomous submergible whole-water samplers. Each of the three categories will become a single chapter in the final product from this project for the executive decision makers at USGS (Appendix B, C, \& D). These chapters exist in a listed format for the simplicity of comparing the mentioned whole-water sampling technology.

\section{Current Lotic System Samplers}

Isokinetic depth-integrating samplers are whole-water sampling technology specific to lotic systems. Isokinetic depth-integrating samplers are designed to accumulate a representative water sample continuously and isokinetically (Lane et al., 2003). An isokinetic sampler refers to a sampler that causes no change in stream velocity upon the sample water entering the sampler intake (Martin et al., 1992). According to Hank Johnson of USGS, an isokinetic depthintegrating sampler is used in conjunction with multiple measurements across a stream or river channel anytime a sample that is representative of the entire cross-sectional profile of a stream or river is needed (personal communication, June 10, 2011). These samplers are an asset in the task of collecting trace elements in the suspended sediment of a cross-sectional profile of a stream or river; however, all classes of analytes can be sampled accurately, except for inorganic gases and VOC/SVOC. The design of the sampler allows air to be displaced and escape from the sample container, thus not capable of obtaining a representative measurement of volatile compounds.

The method of collecting a sample in streams or rivers is by using either an equal-widthincrement (EWI) or equal-discharge-increment (EDI) sampling method. If both methods are used accurately, both should yield identical results, a composite sample that represents the discharged-weighted concentrations of the cross-section of the stream being sampled (USGS, 2006). Both the EWI and EDI methods take into consideration the width of a cross-section of a river/stream to determine how many sample increments are necessary to sample within that cross-section, along with the vertical sampling rate of the sampler based on the velocity of the river/stream.

The USGS use five different models of the sampler based either on hand-held or cableand-reel techniques to operate the samplers. All mentioned isokinetic depth-integrating samplers are made by The Federal Interagency Sedimentation Project (FISP) and are currently in use by USGS. Calibration of the instruments is done at USGS's Hydrologic Instrumentation Facility 
(FISP, n/d.). The different variations and names of the most up-to-date samplers used are: US DH-81, US DH-95, US D-95, US D-96, and US D-99.

As previously mentioned, each model of the sampler has the capability to measure organic and inorganic analytes, depending on the construction materials used on the sampler. The only exception is inorganic gases and VOC/SVOC. For inorganics, such as metals and other trace elements, a fluorocarbon polymer, such as Teflon, or polyproplyene sample container and nozzle can be used. For organic compounds, Teflon or stainless steel attachments can be used with sampler to prevent cross-contamination. Nutrients can be sampled with either material. All information of USGS isokinetic depth-integrating samplers came from USGS National Field Manual for the Collection of Water-Quality Data and from FISP websites (Appendix B).

The US DH-81 is a half-pound hand-held sampler used in shallow wadable streams. This particular model collects the sample by submerging the sampler into the water with the nozzle pointing directly into the flow of the stream or river where then the vertical profile of the stream is measured following the EWI or EDI method. The water and suspended sediment enter the nozzle isokinetically and collect into the sampler container. Air is displaced in the container and exits through an air vent hole in the cap of the sampler. The sample is then transferred into a clean compositing vessel, usually a glass carboy or a churn splitter, where aliquots are pulled from the compositing vessel, filtered if necessary, and placed into bottles dictated by the laboratory for the different analyses requested (Hank Johnson, personal communication, June 10, 2011).

The data quality advantages and issues of the US DH-81 are that the sampler can take an accurate representative sample of the stream or river with a velocity between 2.0 to 6.2 feet per second (ft. /sec) with a 3/16-in nozzle and 1.5 to $7.6 \mathrm{ft}$. / $\mathrm{sec}$ with a 1/4-in nozzle, and 2.0 to 7.0 $\mathrm{ft}$. /sec with a 5/16-in nozzle. Anything outside of this range does not allow for an isokinetic sample. It is recommended that the volume of sample collected not exceed $800 \mathrm{~mL}$ when using a $1 \mathrm{~L}$ sample container and sampling depth should not exceed fifteen feet. If exceeded, isokinetic sampling is no longer obtained due to excessive pressure on the sampler from the weight of the water.

The advantages and disadvantages of the US DH-81 are that it is light weight and easy to use and it can collect a representative sample of current condition of a stream or rivers; however, 
it is depth limited due to being a hand-held sampler. The cost of the sampler is unknown but assumed to a couple hundred dollars.

The US DH-95 is a \$2,556.00 hand-held or cable-and-reel sampler used in medium velocity streams or rivers. The sampler weighs twenty-nine pounds and is made of bronze that is coated with plastic. The cable-and-reel method is more favored due to the weight of the sampler. The sampler containment construction materials are either a $1 \mathrm{~L}$ polypropylene or a $1 \mathrm{~L}$ Teflon container so both organic and inorganic analytes can be collected.

The cable-and-reel method is performed by lowering and raising the sampler into the water at a constant transit rate through the water column. The sampler should be connected to a hanger bar and the hanger bar to a suspension cable. The sample is then collected by submerging the entire sampler into the flow of the stream or river at desired depth where then water and suspended sediment enter the nozzle and collect into the sampler container. Air is displaced in the container and exits through an air vent hole in the cap of the sampler. The sample is then transferred into necessary storage containers, similar to previously mentioned.

The data quality advantages of the US DH-95 are that the US-DH 95 can take an accurate representative sample of a stream or river with a velocity between 1.7 to $7.4 \mathrm{ft}$. $/ \mathrm{sec}$, depending on the nozzle diameter in use. It is recommended that the volume of sample collected not exceed $800 \mathrm{~mL}$ when using a $1 \mathrm{~L}$ sample container. If exceeded, isokinetic sampling is no longer obtained due to risk of overfilling the sample container. Sampling depth should not surpass 13.3 - $15 \mathrm{ft}$., depending on nozzle size. A disadvantage of using the US DH-95 is due to the weight of the sampler, a hanger bar and suspension cables need to be used, usually connected to a crane from a bridge suspended over a river channel. A crane on a boat can also be used for sample collection; however this method is used less frequently due to the cost and complexity of sampling from a boat (Hank Johnson, personal communication, June 10, 2011).

The US D-95 is a $\$ 2,958.00$ sixty-four pound plastic dip coated bronze sampler used for collecting a depth-integrated flow-weighted suspended sediment sample in streams or rivers. The suspension method is cable-and-reel. The sample container of the US D-95 is either $1 \mathrm{~L}$ plastic container or a $1 \mathrm{~L}$ Teflon container, thus organics or inorganics can be sampled.

The sampling method of the US D-95 is similar to the US DH-95 cable-and-reel method. The US D-95 can take an accurate representative sample of a stream or river with a velocity between 1.7 to $6.7 \mathrm{ft}$. /sec, depending on the nozzle diameter. It is also recommended that the 
volume of sample collected to not go above $800 \mathrm{~mL}$ when using a $1 \mathrm{~L}$ sample container. If exceeded, isokinetic sampling is no longer obtained. Sampling depth should not exceed 13.3 $15 \mathrm{ft}$., again depending on nozzle size. The advantages and disadvantages of the US D-95 are the same as the US DH-95.

The US D-96 is a \$5,741.00 132 pound depth-integrating collapsible bag sampler which can sample up to $3 \mathrm{~L}$ while being operated by the cable-and-reel method. The sampler is made of bronze and aluminum, all metal plastic dip coated. The sampler container is either a bag made from perfluoroalkoxy or polyethylene so either organics or inorganics can be sampled.

The sampling method for the US D-96 is the same as the cable-and-reel method as used by the US D-95. The US D-96 can take an accurate representative sample of the stream or river with a velocity between 2 to $12.5 \mathrm{ft}$. /s, depending on nozzle size. The sampler has a maximum transit rate, the vertical lowering and raising of the sampler through the water column, of fourtenths times the streams velocity. There is no minimum transit rate, as long as the sampler container volume is not exceeded. The sampler can sample to depths of 39-110 ft., depending on nozzle size. As stated before, the advantages and disadvantages are similar to models mentioned above. Disadvantages are primarily due to the weight of the sampler.

The US D-99 is a 285 pound depth-integrating collapsible bag sampler which can use $3 \mathrm{~L}$ or $6 \mathrm{~L}$ sample bags and is operated by cable-and-reel. The sampler is made of bronze and aluminum where all metal is plastic dip coated. The sampler container is either a perfluoroalkoxy bag or a polyethylenes bag, so either organics or inorganics can be sampled.

The sampling method is the same as the cable-and-reel method mentioned above. The US D-99 can take an accurate representative sample of the stream or river with a velocity up to $15 \mathrm{ft}$. /s. The sampler can sample to depths of 78-220 ft. depending on nozzle size. The advantages and disadvantages are similar to those heavier models mentioned above. The cost of the sampler is unknown.

Research on lotic system samplers has concluded that there are no emerging technologies that could replace current isokinetic depth-integrating sampler for analysis of stream and river conditions. The USGS is currently using the best option in collecting a representative wholewater sample, especially regarding suspended sediment collection. Therefore, there are no recommendations for sampling method or technological improvements for USGS to reduce cost, improve efficiency, and increase data analysis for lotic specific systems. 


\section{Portable Autonomous Whole-Water Samplers}

Portable autonomous whole-water sampler pumps, also known as automatic samplers, are devices that allow for a number of samples to be obtained at pre-set intervals without the commitment of personnel to manually take samples for water quality analysis (Kotlash et al., 1998). This technology can be used in a variety of bodies of water such as lakes, reservoirs, groundwater wells, rivers, and streams. These pumps are typically deployed at locations near but out of the water, have a tube that goes into the water at desired depth, and have the sampler mechanically pump water into a collection container according to pre-programmed intervals, by using a vacuum or peristaltic pump system. Autonomous whole-water sampling pumps can perform composite and/or discrete sampling, depending on make and model of pump.

Research resulted in difficulty in determining what automatic sampler pumps are currently being used by USGS as USGS does not endorse a specific product line or source, according to Stanley C. Skrobialowski of USGS (personal communication, April 4, 2011). It was then determined to investigate and evaluate the most current automatic sampler technology on the market and to find scientific advances in this field of technology. After completing an indepth literary examination by finding journal articles that used specific pumps and of exhibit participants of former National Water Quality Monitoring Council Summits, it has been determined that the manufacturers of current portable autonomous whole-water samplers useful to USGS are Aquamatic, SIRCO, and ISCO.

Aquamatic is a company based out of Manchester, UK that specializes in automatic wastewater and water quality sampling equipment. Aquamatic makes the Aquacell P2COMPACT, Aquacell P2-MULTIFORM, \& Aquacell-COOLBOX for the collection of water quality samples. Information on Aquamatic's pumps can be found on Aquamatic's websites (Appendix C).

The Aquacell P2-COMPACT is a composite sampler capable of sampling up to $5 \mathrm{~L}$ in volume that can take up to $350+$ composite samples at predetermined intervals. Aquacell P2COOLBOX is a composite sampler capable of sampling up to $5 \mathrm{~L}$ in volume. The COOLBOX sampler is capable of refrigerating the sample container up to 5 days and can also take 350+ composite samples at predetermined intervals. Aquacell P2-MULTIFORM is Aquamatic's discrete sampler, capable of sample options of 12 x $1 \mathrm{~L}, 12 \times 0.75 \mathrm{~L}, 4 \times 5 \mathrm{~L}$, and 4 x $4.5 \mathrm{~L}$ samples at predetermined intervals. 
The three samplers are all capable of collecting whole-water samples to determine the presence of organic and inorganic analytes along with nutrients. The construction materials of the three samplers consist of two options. The first is a polypropylene sample chamber top, braided polyvinyl chloride (PVC) tubing to collect the sample, and polypropylene sample containers to measure inorganics and metals. The second option is a polytetrafluoroethylene (Teflon) sample chamber top, a braided Teflon sample tube, and glass sample containers to measure organic analytes. Volatile compounds are not recommended for sampling as there is a head space in the sample container which causes volatiles to escape sample prior to analysis.

The reason for mentioning samplers made by Aquamatic is that one of the models is capable of self-refrigeration. According to Kotlash et al., 1998, automatic samplers may not be retrieved for several days, thus resulting in alteration of the water quality characteristics induced by a lack of refrigeration. This is especially true for nutrients. The refrigeration capability of the Aquacell P2-COOLBOX is a good fit for USGS if sample preservation is an issue for a specific sampling event.

The second manufacturer of portable autonomous whole-water sampler is SIRCO. SIRCO makes three whole-water samplers, PVS 4100, PVS 4120, \& PVS 4150. Information on SIRCO pumps came from SIRCO's websites (Appendix C). All three samplers are able to collect a representative whole-water sample for water quality analysis in any body of water. SIRCO samplers are advertised to have the options to interchange the intake hose with either Nylon reinforced PVC to allow for sampling of metals and inorganic analytes or Teflon-lined PVC tubing for organic analytes.

The PVS 4100 is both a composite and discrete sampler capable of taking 24 x $0.5 \mathrm{~L}$ and 24 x 1 L discreet samples. PVS 4100 can operate up to 168+ hours and sample with a sampling tube up to 250 feet away, depending on vertical lift. The PVS 4120 is a smaller version of the PVS 4100 and can only operate up to 84+ hours and sample from 200 feet away, again depending on vertical lift. The PVS 4150 is a composite capable of collecting up to $9 \mathrm{~L}$ of sample, sampling at predetermined intervals, and is capable of taking samples up to 250 feet away, also dependent on vertical uplift.

The PVS 4100 and the PVS 4120 are versatile samplers as they are capable of composite and discrete sampling. Both samplers can draw water from a couple hundred feet through a sample tube and can operate between three to seven days without external power, depending on 
sample volumes and intervals. The three samplers are light weight and easy to use and are capable of sampling organic and inorganic analytes based on the construction materials used.

Finally, the last suggested manufacture for portable autonomous whole-water samplers is Teledyne ISCO. ISCO also makes three automatic samplers capable of collecting whole-water samples for water quality analysis in any body of water for both organic and inorganic analytes due to interchangeable PVC or Teflon sampling components. The three automatic samplers are the ISCO 3710, ISCO 6712, and the ISCO 6712 C. Information on the samplers came from Pine Environmental Services, Inc. websites (Appendix C).

The ISCO 3710 is a composite sampler capable of collecting up to 2.5 gallons in a glass container or 4 gallons into a polyethylene bottle. This sampler can operate up to 24 individual sampling events that can be pre-set at various time intervals. The ISCO 6712 is the same as the ISCO $6712 \mathrm{C}$, but two inches larger in diameter (20 inches). Finally, the ISCO $6712 \mathrm{C}$ is both a composite and discrete sampler capable of multiple sample bottle arrangement options ranging from $24 \times 0.5 \mathrm{~L}$ to $1 \times 5.5 \mathrm{gal}$ and can sample up to a maximum vertical lift of 28 feet. Samples can be taken at predetermined time intervals.

The ISCO 6712 and ISCO $6712 \mathrm{C}$ are beneficial sampler as they are also advertised as being capable of being submerged in water as well as operating above the water surface. This allows for a deeper and wider range of sampling capability, meeting the demands of various USGS sampling events. These two samplers are also capable of containing ice to help keep the samples preserved in the field before being retrieved.

Research has concluded that there are no emerging technologies that could replace current portable automated whole-water samplers on the market today. According to Kirk P. Smith of USGS, most of the technological improvements to the portable sampler design over the past 10-15 years have involved various options of sample bottle sizes and number of sample bottles for discrete sampling (personal communication, April 11, 2011). Other than these advances, the portable water samplers have not progressed much.

As stated prior, it was difficult in determining which automatic sampler pumps to recommend to USGS as USGS does not endorse a specific product line. However, it is recommended that USGS investigate further the use of the Aquacell P2-MULTIFORM, Aquacell P2-COOLBOX, SIRCO's PVS 4100 and the PVS 4120, and the ISCO 6712 and ISCO 6712C automatic pumps. The use of these samplers can cut labor costs due to their capability of being 
in the field for long durations. Also, being the latest in pump technology on the market today assures minimal operation failure and improved data accuracy in collecting a representative whole-water sample.

\section{Current Autonomous Submergible Whole-Water Samplers}

Autonomous submergible whole-water samplers can be programmed to take samples automatically at various time intervals while completely submerged in a body of water at a desired depth. Samplers collect a sample of water that is representative of the current condition of a body of waters. The technology mentioned below is typically applied to oceanic research, meeting the demands of harsh environments. However, many of these ocean whole-water sampler technologies have the potential to be applied to lake and large river environments. The use in streams is not applicable due to the large size of the technology. If applied by USGS, labor cost can be reduced due to the capability of the samplers to be deployed in the field for long durations and improve data collection due to their accurate and precise sampling capability.

The samplers operate by being deployed in aquatic environments and have the facility to automatically collect samples. Typically, the samplers are time-series samplers capable of collecting multiple individual samples and can be fitted with a variety of filters and stabilizing solutions. The samplers mentioned below can be deployed for a few hours or up to a year, depending on the predetermined sampling intervals. During deployment, the unit can record data including sample collection timing, flow rate, volume, and even real-time data. The main mechanical components of each sampler includes a watertight pressure-resistant housing, a pump assembly, a multi-port valve, and sample containers. The sampler can be anchored to an ocean, lake, or river bed or be tethered to a surface vessel. Most samplers have locations on them to attach additional sensors while deployed in the field, making the most of a sampling event.

The samplers examined are the: "Remote Access Samplers", "Environmental Process Sampler”, "Phytoplankton Sampler", “Zooplankton Sampler”, and "Large Volume Pump” from McLane Labs; the "M1018S Series Syringe Sampler Rosette®” from General Oceanics; and finally a twelve "50 mL Syringe Sampler" from KC Denmark. All samplers are whole-water samplers used for various water quality analyses. Information on the specific technology came from various company or research laboratory websites resulting from an on-line web search of autonomous submergible whole-water samplers (Appendix D). 
McLane Labs from Falmouth, MA makes the "Remote Access Sampler" (RAS) in 100 and $500 \mathrm{ml}$ sample collection volumes, called the RAS-100 and RAS-500. The RAS samplers can be used up to 6,000 meters in depth for multiple time-series sampling events. Studies where the RAS units are used consists of ambient water quality data, suspended materials, biological information, dissolved nutrients, trace metals, and dissolved organic carbon. The construction materials that come in contact with the sample are either metalized polyethylene lined or Tedlar sample containers, and HYDROX plastic valve stators or a Kynar plastic rotor for the sampling multiport valve.

The representative whole-water sample is collected via a peristaltic pump at predetermined intervals. The RAS-100 collects 48 different $100 \mathrm{~mL}$ samples while the RAS-500 collects 48 different $500 \mathrm{~mL}$ samples. Both units have the capability to mount additional probes onto the unit for further analyses in water quality. Data is analyzed after the unit is retrieved in the laboratory. The RAS device can collect samples from ocean, lake, or river bed or from a specific depth when tethered to a surface vessel. Depth profiles are not typically done with these devices, thus these devices can only report on water quality from their deployed depth. Samples collected in this manner can be tested for accuracy through the use of replicates to maintain quality control and assurance.

The advantages of the RAS unit is its ability to collect multiple discrete samples under extreme depth and pressure from a single point over a given time period in a regimented timeseries. The disadvantages of this technology include the lack of depth profile, as this device is stationary, typically sitting on the floor of the body of water it is sampling. The cost of the RAS is unknown and one must inquire to McLane Labs for pricing.

The "Environmental Process Sampler" (EPS) also comes from McLane Labs and is designed for the collection and analysis of water quality up to $50 \mathrm{~m}$ in depth to determine microorganisms and their gene products. This technology has the capability to take discrete whole-water samples of concentrated microorganisms and particles and can analyze the gene product of microorganisms in the field while sending real-time data back to the laboratory.

The EPS identifies taxa of microorganism by using sandwich hybridization chemistry and nucleic acid probes to identify target taxa and can be deployed in the environment up to three months while transmitting real-time data of hybridization assays. Water samples can also be collected for parallel analysis ensuring quality control. 
The advantages of the EPS are its ability to collect samples under extreme depth and pressure, with a large number of replicates collected in a regimented time-series. The EPS is not advertised for fresh water environments but no limitations to freshwater environments are told. The cost of the EPS is unknown and one must inquire to McLane Labs for pricing.

The "Phytoplankton Sampler" (PPS), which is designed for automatic collection of particulates onto a membrane filter in aquatic environments up to 5,500 $\mathrm{m}$ deep and is capable of measuring phytoplankton, trace metals, and suspended particles. McLane Labs manufactures the PPS and one must inquire to McLane Labs for a price estimate.

The PPS gathers a sample of particulates that are filtered through a $47 \mathrm{~mm}$ filter, capable of collecting twenty-four discrete samples, each with a maximum filter volume of $10 \mathrm{~L}$ per filter. The device can be deployed up to fourteen months unattended for time-series regimented data collection. Research has shown that the PPS is not yet utilized in fresh water environments but nothing states that it cannot be used in fresh water phytoplankton studies.

McLane Labs also makes the "Zooplankton Sampler" (ZPS) which is designed for in-situ automatic collection of zooplankton. Sampling is done with a flexible predetermined time-series sampling schedule based on experimental needs. The ZPS is capable of taking 50 individual zooplankton samples that are collected and preserved on a mesh collection belt for study by filtering a water sample through the mesh filter. Other belt materials advertised are made of aluminum foil or urethane for necessary sampling procedures. The ZPS devise can be deployed up to a year depending on pumping rates and can be used up to 5,000 meters in depth. Similar to the other McLane Lab technology, the ZPS is not advertised for freshwater environments but could be applied when zooplankton data is required for study.

The last technology mentioned by McLane Labs is the "Large Volume Pump" (WTS-LV) which is designed for a single event in-situ automatic collection of suspended and dissolved particulates onto a Black Acetal $142 \mathrm{~mm}$ membrane filter. The WTS-LV collects suspended and dissolved particulates, trace metals, chlorophyll, and phytoplankton by taking a single event sample. A desired volume of water is filtered through a membrane at rates slow enough to not destroy the sample. Samples can be observed on the membrane filter in the lab. The device can be used up to 5,000 meters in depth and filter a range of 2,500 - 15,000 L of water, depending on membrane. The WTS-LV is not advertised for freshwater environments but could be applied for single sampling events. 
General Oceanics from Miami, FL makes the "M1018S Series Syringe Sampler Rosette ${ }^{\circ}, "$ which is a multiple bottle sampling array designed to take water samples at any depth using 12-24 individual $10 \mathrm{~mL}$ or $60 \mathrm{~mL}$ glass or disposable syringes. Depending on the construction material of the syringes used, typically polypropylene, glass, or Teflon, will determine what chemical classifications can be sampled for without contaminating the sample. General Oceanics makes a number of multiple bottle sampling arrays to meet various sample volume demands. The M1018S is the smallest sample size array General Oceanics manufactures.

The M1018S sampler operates by having a conducting cable attached to the sampler. The conducting cable is capable of telling the sampler when to take a sample through manual operation, or it can be programmed to take samples at a predetermined time interval at a desired depth unattended. The M1018S cost \$20,760.00.

There are several advantages and disadvantages to the M1018S. The sampler can operate at any depth (maximum depth is unknown) by being mounted on an anchor at various depths in a given body of water and can be programmed to take samples at predetermined intervals unattended. The sampler is also small enough for a one person to deploy and retrieve. More interesting, Breier et al. (2009) attached a rosette multi-sampler to a remotely operated vehicle for vertical-profiling. This can be a huge advantage in deep lakes when interested in sampling the vertical profile of the water column. The disadvantage is the expensive cost and the fact that the sampler is not advertised for freshwater environments, however, the use in lakes and rivers is not unmanageable.

The final current autonomous submergible whole-water sampler on the market worthy of mentioning for USGS is the " 24 Volt DC Motor Driven Multiple Water Station with 12 pcs 50 ml Syringes," made by KC Denmark from Silkeborg, Denmark. This sampler is a multiple bottle sampling array designed to take water samples using twelve individual $50 \mathrm{~mL}$ nylon PA 6.6 syringes, however, polypropylene or Teflon syringes can too be used on the sampler. A conducting cable is attached to the sampler, manually telling the sampler to take a sample, or it can be programmed to take samples at predetermined time intervals unattended.

The advantages of KC Denmark sampler is that the sampler can obtain a sample at any depth up to $6,000 \mathrm{~m}$ and can be programmed to take samples at predetermined intervals unattended. The sampler is small enough where no mechanics are needed to lower and raise the 
sampler and like the M1018S, it too can be attached to a remotely operated vehicle. The cost of KC Denmark's sampler is unknown and it is recommended to contact KC Denmark directly for price. The disadvantage is that the sampler is not advertised for freshwater environments, but the sampler could be applied to lake and river environments for whole-water analysis.

\section{Emerging Autonomous Submergible Whole-Water Samplers}

The literature investigation of USGS websites, water sampling technology manufacturing company websites, and participants of past water council summits had shown difficulty in producing results for emerging technology in whole-water sampling. It was only through a Google patent search using various whole-water sample key words, similar to the literature search, which produced two results for emerging whole-water sample technology. The two emerging autonomous submergible whole-water sample technologies are the "Boat Including Automated Water Sampling Device \& Method of Using the Same" and the "Bed Water Sampling Device.”

"The Boat Including Automated Water Sampling \& Method of Using the Same" is an invention created by Carl J. Lange and is found in the United States Patent Application Publication US2010/0095789 A1 on April 22, 2010 (Appendix D). The invention is a small boat that is remotely operated from shore by a multi-channel radio control unit and is powered by a solar hydrogen electrochemical reactor. The sampler is attached to the belly of the boat and is designed to take up to four discrete samples in glass test tubes. The sampler could easily be manipulated for an increase in the number of sample containers. The boat can be operated on any body of water while being controlled by an operator who can control the movement of boat and a sampling apparatus from the multi-channel radio control unit from dry land.

The sampling device is designed for a plurality of sampling tubes that can be programmed to take multiple samples at a variety of depths in a body of water. The sampler is attached to a robotic winch that lowers and raises the sampler. Sampling tubes are attached to a disk which can rotate around a second disk, which holds on an aperture that allows water flow for sampling. For quality assurance and quality control, replicates of samples collected can be obtained for data accuracy and precision.

The advantage of Lange's invention is that the sampler can sample in heavily contaminated water that could be harmful to field technicians. The boat and sampler are 
remotely operated safely from the shore of the body of water being sampled. The sampler design is potentially capable of manipulation, thus allowing variation in the number of samples that can be deployed and various materials used for sampling to obtain nutrients and organic or inorganic analytes. The ease of operation is yet apparent but should be comparable to a recreational remote operated boat, but on a larger scale.

The second emerging technology studied is the "Bed Water Sampling Device". The "Bed Water Sampling Device" is an invention created by Eberhard J. Sauter assignee of Stiftung Alfred-Wegener-Institut (AWI) Fuer Polar-und Meeresforschung from Bremerhaven, Denmark. The device is found in United States Patent US7,757,573 B2 from July 20, 2010 and information also came from AWI website (Appendix D). The "Bed Water Sampling Device" is an improved bed water sampler used to capture a more accurate representative sample of bed water in the ocean; however, this sampler can be used for bed water analysis in lakes and large river systems. The main purpose of the sampler is for biogeochemical and microbiological investigations. Bed water is the transitional zone between sediments and the water several feet above it (Sauter et al., 2005).

The "Bed Water Sampling Device" consists of multiple horizontal sample containers at different heights from the water bed that can rotate to align directly with the water flow, allowing free flow of water through the sample container until sample is collected. The sample is collected by sealing the open ends of the container simultaneously to capture a sample of water. The sampler is anchored to the water bed and collects samples with a time-controlled release. For quality assurance and quality control, replicates of samples collected can be obtained for data accuracy and precision.

When compared to other bed water samplers, this sampler is the only sampler that freely rotates in the water column to align with the direction of water flow. This bed water sampler is unique because it uses a design that captures the water sample by closing both sides as opposed to a suction mechanism, which Sauter et al. argues could prevent an accurate representative whole-water sample.

\section{Conclusion of Project}

An investigation on current and emerging surface water sampling technologies, comparisons of those technologies, and recommendations as to what technologies should be 
adopted by USGS for implementation in the NAWQA Program was conducted. The importance of this project was to supplement USGS management with enough material to make an informed decision as to what current and emerging whole-water sampling technologies should be adopted and used by USGS in hope to reduce labor cost, increase effectiveness, and data accuracy. The categories of technology examined involved isokinetic depth-integrating samplers for lotic systems, portable autonomous whole-water samplers, and autonomous submergible whole-water samplers.

In terms of lotic systems, USGS is using the most current and up-to-date technology that can take a representative whole-water sample from a moving water body, isokinetic depthintegrating samplers. This category of sampler is capable of sampling for emerging organic and inorganic emerging contaminants, major ions, nutrients, PCB, pesticides, and trace elements, and suspended sediment. Research has shown that there is no emerging technology in this field to replace current sampling practices. Thus, there are no recommendations to USGS for making improvement on lotic system whole-water sampling.

USGS should consider implementing the latest portable autonomous whole-water samplers out on the market. This investigation and evaluation of current and emerging wholewater sampling technologies has concluded that USGS could benefit from the latest in portable automatic water samplers, such as the Aquacell P2-COOLBOX, SIRCO models PVS 4200 and the PVS 4120, and the ISCO 6712 and ISCO 6712C.

Use of the Aquacell P2-COOLBOX is advised if sample preservation is an issue as the sampler is capable of self-refrigeration. The Kotlash et al. (1998) study demonstrated that when sampling for nitrogen and phosphorus species with automatic samplers, the lack of preservation for two days can significantly change the concentrations in the sample, making the sample neither representative nor accurate of the current water quality conditions. The SIRCO models PVS 4100 and the PVS 4120 are excellent samplers as they are capable of both composite and discrete samples, making them versatile for various experimental designs. SIRCO samplers also have the 24 x $0.5 \mathrm{~L}$ discrete sample orientation. Smaller sample volumes are ideal for remote sample locations as water is heavy in weight and can be difficult to transport, therefore improving efficiency. Similarly, the ISCO 6712 and ISCO $6712 \mathrm{C}$ have the $24 \mathrm{x} 0.5 \mathrm{~L}$ sample orientation. ISCO samplers are recommended for use as these automatic pumps can be submerged in water and have refrigeration capability through the use of ice. 
The decision to adopt the mentioned portable autonomous whole-water samplers is costeffective. These samplers can cut labor costs due to their capability of being in the field for long durations, making less need for site visits, and being the most recent pump technology assures accuracy in collecting a whole-water sample for analysis. The self-refrigerating models can also be used to improve data accuracy when sampling for parameters sensitive to temperature, such as nutrient concentrations. The portable autonomous whole-water samplers come with various sampling materials to measure both organic and inorganic analytes.

For autonomous submergible whole-water samplers, this investigation has determined that there are numerous options to choose from currently on the market today. The drawback with autonomous submergible whole-water samplers is that they are primarily advertised for oceanic studies, making them costly. However, these samplers are very durable and well-built, meeting the demands of being in harsh environments for long periods of time. These state-ofthe-art samplers can undoubtedly be incorporated into USGS fresh water lake and large river studies improving data collection and reducing costs for water quality analysis. The use in streams is not foreseen due to the technology being on the larger side and would not be successful in sampling in shallow streams.

For USGS purposes of freshwater whole-water sampling alone, McLane Labs RAS-100 can be implemented in lakes and large rivers for various water quality analyses. Use of the RAS100 is recommended for studies when small sample volumes are required as the RAS-100 can collect up to 48 different $0.1 \mathrm{~L}$ individual samples. Smaller sample volumes to transport out of the field allows for more efficient work and decreases labor cost as less trips back and forth from the field site will be required. The RAS-100 sampling unit can also be deployed for several months unattended if desired. Ability to be self-powered for several months again reduces costs due to less site visit requirements for battery maintenance.

The General Oceanic “M1018S Sampler Rosette®” and the KC Denmark “24 Volt DC Motor Driven Multiple Water Station" would also be great additions for USGS sampling when small sample volumes are needed, such as gas chromatography-mass spectrometry analysis where only microliters of sample are needed. The M1018S can sample from 12 to 24 individual samples ranging from 10-60 mL in volume, while the KC Denmark sampler can sample 12 individual $50 \mathrm{~mL}$ sample. Both samplers can utilize syringes made from different material so 
sampling of organic and inorganic analytes can be obtained. Smaller sample volumes are also preferred when in remote locations when having to hike in and out a lot of field equipment.

For emerging whole-water sampling technology, it is recommended that USGS looks into the two emerging technologies mentioned above, the "Boat Including Automated Water Sampling Device \& Method of Using the Same" and the "Bed Water Sampling Device." The "Boat Including Automated Water Sampling Device \& Method of Using the Same" invention is a sampler that can be operated from shore, making this technology favored when sampling in areas of lakes and rivers that are difficult to access. Having technology that aids in helping expanding the range of data collection is most certainly economical and seeing that this technology is recently patented, USGS could potentially buy the patent for a reasonable price. The "Bed Water Sampling Device" invention may be of interest to USGS for bed water sampling. This sampler is the latest of its kind, improving data quality by freely rotating in the water column for optimal representative sampling of lakes and large river systems. If implemented, USGS could save on cost and increase data content collected. 


\section{References}

Brier, J.A., Rauch, C.G., McCartney, K., Toner, B.M., Fakra, S.C., White, S.N., German, C.R. 2009. A suspended-particle rosette multi-sampler for discrete biogeochemical sampling in low-particle-density waters. Deep-Sea Research I. 56: 1579-1589.

Cech, T.V. 2003. Principles of Water Resources: History, Development, Management, and Policy Third Edition. Hoboken, NJ: John Wiley \& Sons, Inc.

[FISP] Federal Interagency Sedimentation Project. n./d. Retrieved on April 28, 2011 from: http://fisp.wes.army.mil/Catalog_Index.htm.

[HBSL] Health-Based Screening Level Home. 2008. Retrieved on June 9, 2011 from USGS website: http://infotrek.er.usgs.gov/apex/f?p=169:30:0::NO:RP:...

Kalff, J. 2002. Limnology: Inland Water Ecosystems. Upper Saddle River, NJ. Prentice-Hall, Inc.

Kotlash, A.R., Chessman, B.C. 1998. Effects of Water Sample Preservation and Storage on Nitrogen and Phosphorus Determinations: Implications for the Use of Automated Sampling Equipment. Water Resources. 32:12 3731-3737.

Lane, S.L., Flanagan, Sarah, and Wilde, F.D., 2003, Selection of equipment for water sampling (ver. 2.0): U.S. Geological Survey Techniques of Water-Resources Investigations, book 9, chap. A2, March, accessed_date_ at http://pubs.water.usgs.gov/twri9A2/.

Lepoam, P., Brown, B., Hanke, G., Loos, R. Quevauviller, P., Wollgast, J. 2009. Needs for Reliable Analytical Methods for Monitoring Chemical Pollutants in Surface Water Under the European Water Framework Directive. Journal of Chromatography A. 1216: 302315.

Martin, G.R., Smoot, J.L., White, K.D. 1992. A Comparison of Surface-Grab and Cross Sectionally Integrated Stream-Water-Quality Sampling Methods. Water Environment Research. 64:7 886-876.

Sauter, E.J., Schluter, M., Wegner, J., Labahm, E. 2005. A Routine Device for Hight Resolution Bottom Water Sampling. Journal of Sea Research. 54, 204-210.

[USGS] U.S. Geological Survey, 2006, Collection of water samples (ver. 2.0): U.S. Geological Survey Techniques of Water-Resources Investigations, book 9, chap. A4, September, accessed__date__ at http://pubs.water.usgs.gov/twri9A4/.

[USGS] United States Geological Survey. 2010. National Water-Quality Assessment ProgramScience to Policy and Management. Retrieved on January 6, 2011 from: http://water.usgs.gov/nawqa/xrel.pdf. 
[USGS] United States Geological Survey. 2011. About USGS. Retrieved on April 2, 2011 from: http://www.usgs.gov/aboutusgs/.

Wilde, F.D., Radtke, D.B., Gibs, Jacob, and Iwatsubo, R.T., eds., 2004 with updates through 2009, Processing of water samples (version 2.2): U.S. Geological Survey Techniques of Water-Resources Investigations, book 9, chap. A5, April, accessed June 9, 2011 at http://pubs.water.usgs.gov/twri9A5/ (Separate updates for 5.3.2, "Instructions for field use of spike solutions for organic-analyte samples", 5.6.1.F, "Wastewater, pharmaceutical, and antibiotic compounds," 5.6.4.A, "Arsenic speciation," and 5.6.4.B, "Low-level Mercury" are provided on the Web page.). 


\section{Appendix A}

Master Outline of Current and Emerging Water Quality Sampling Technologies by U.S. Geological Survey National Water-Quality Assessment (NAWQA) Program.

A1.0 Existing Water Quality Sampling Methods (mention if used by USGS)

1.0 Background and Theory of Sampling Method

1.0.1 Basic description

- What aquatic environments are being observed with this method

1.0.2 How many variations of technology

1.0.3 Types of data obtainable

- Organic vs. inorganic

- Qualitative vs. quantitative

A1.1 Specific Current Water Quality Sampling Technology. (Each individual technology will follow the format of having a background/theory, QA/QC, cost, and advantage and disadvantage. We will have to number appropriately, maybe a letter in front of section. Ex) A1.1 or B1.1).

1.1 Background and Theory of (name of technology)

1.1.1 General information

- Aquatic environments used in.

- Environment: Lakes, rivers, swamp, etc...

- Situations: Grab/integrated, depth-integrating, etc...

1.1.2 What data is being analyzed/gathered

1.1.3 Sample methodology/Data collection

- How is the sample collected

- How is data collected and stored

1.2 Data Quality Advantages and Issues

- General accuracy and precision

- Discussion of QA/QC

\subsection{General Cost Considerations}

1.3.2 Field and laboratory time and material requirements

1.3.2.1 Cost of sampling instrument

1.3.2.2 Cost of storage and transport

1.3.2.3 Cost of sample analysis

1.3.2.4 Cost of human labor to operate/deploy sample technology

1.4 Advantages and Disadvantages of (name of technology)

- Overall advantages and disadvantages of using this method 
A1.3 Tables to Compare and Contrast Technologies

(Review specific technologies. This could be put in/organized by use of a table rather than as a lot of text???? would facilitate comparisons $=>$ could go to oversize format in landscape....USGS loves tables how about thinking what this table might look like as a summary and then use it to come up with the outline for this section)

\begin{tabular}{|l|l|l|l|l|l|l|l|l|}
\hline & analytes & water types & mechanism & etc. & & & & \\
\hline 1. xxxx & & & & & & & & \\
\hline 2. yyyy & & & & & & & & \\
\hline 3. zzzz & & & & & & & & \\
\hline 4. aaaa & & & & & & & & \\
\hline
\end{tabular}

B1.0 Evaluation of Emerging Water Quality Technologies. (Each new individual technology will follow the format of having a background/theory, QA/QC, cost estimation, and advantage and disadvantage. We will have to number appropriately).

Specific emerging technologies (name of technology)

1.0 Background/Theory

- Specifically in what environment and what situations you would use this current technology.

- What data is being analyzed/gathered

- When the technology is used

- Mechanisms of the technology

1.1QA/QC

- Methods of using technology

\subsection{Cost estimation}

1.2.1 Field and laboratory time and material requirements

1.2.2 Cost of sampling instrument

1.2.3 Cost of storage and transport

1.2.4 Cost of sample analysis

1.2.5 Cost of human labor to operate/deploy sample technology

1.3 Advantages and disadvantages of this specific technology

B2.0 Tables to Compare and Contrast Technologies

(Review specific technologies. This could be put in/organized by use of a table rather than as a lot of text???? would facilitate comparisons => could go to oversize format in landscape....USGS loves tables how about thinking what this table might look like as a summary and then use it to come up with the outline for this section)

\begin{tabular}{|l|l|l|l|l|l|l|l|l|}
\hline & analytes & water types & mechanism & etc. & & & & \\
\hline 1. xxxx & & & & & & & & \\
\hline 2. yyyy & & & & & & & & \\
\hline 3. zzzz & & & & & & & & \\
\hline 4. aaaa & & & & & & & & \\
\hline
\end{tabular}


C1.0 Comparison and conclusion

1.0 Comparison

- Compare and contrast between old vs. new

- Accuracy/precision

- Ease of deployment and operation

- Efficiency

1.1 Conclusion

- Cost-benefit analysis (if applicable)

- Is the idea of replacing old technologies with new technologies reasonable?

- Recommendations as to what technologies should be adopted by the Survey 


\section{Appendix B}

Lotic Water System Sampler Chapter

A1.0 Current Water Quality Sampling Methods for Lotic Water Systems

2.0 Isokinetic Depth-Integrating Samplers as used by USGS

1.0.1 Basic description

- Isokinetic depth-integrating samplers are whole-water sampling technology specific to lotic systems. Isokinetic depth-integrating samplers are designed to accumulate a representative water sample continuously and isokinetically (Lane et al., 2003). Isokinetic refers to how the velocity of the stream/river does not change when the water sample enters the sampling unit. According to Hank Johnson of USGS, an isokinetic depth-integrating sampler is used in conjunction with multiple measurements across a stream or river channel anytime a sample that is representative of the entire crosssectional profile of a stream or river is needed (personal communication, June 10, 2011).

- The method of collecting a sample in streams or rivers is by using either an equal-width-increment (EWI) or equaldischarge-increment (EDI) sampling method. If both methods are used accurately, both should yield identical results, a composite sample that represents the discharged-weighted concentrations of the cross-section of the stream being sampled (USGS, 2006). Both the EWI and EDI methods take into consideration the width of a cross-section of a river/stream to determine how many sample increments are necessary to sample within that cross-section, along with the vertical sampling rate of the sampler based on the velocity of the river/stream.

- USGS uses five isokinetic depth-integrating samplers, all of which are made by The Federal Interagency Sedimentation Project (FISP) and are calibrated USGS's Hydrologic Instrumentation Facility.

- Two types of samplers are used, hand-held and cable-and-reel. Cable-and-reel samplers collect water samples by raising and lowering the sampler at a constant rate in the vertical profile of the stream. Rate of vertical movement, transit rate, will depend on sampler size.

- All information on the isokinetic depth-integrating samplers came from USGS National Field Manual for the Collection of Water-Quality Data, Chapters A2, A4, and from various FISP 
website links found at:

http://fisp.wes.army.mil/Catalog_Index.htm

1.0.2 Variations of Isokinetic depth-Integrating Samplers

- The USGS uses five different designs of isokinetic samplers depending on stream/river velocity. Velocity ranges from $1.5-$ $15 \mathrm{ft}$. /s. Two types of samplers are used and are categorized by method of suspension in the water body: Hand-held and Cable-and-Reel.

○ Hand-held:

- US DH-81

○ Hand-held or Cable-and-Reel:

- US DH-95

○ Cable-and-Reel:

- US D-95

- US D-96

- US D-99

1.0.3 Types of data obtainable

- Organic \& inorganic contaminants, trace elements, major ions, PCB, pesticides and suspended sediment can be collected depending on material of the sampler components. Sample containers are typically made from fluorocarbon polymers, Teflon, stainless steel, or ceramics.

\section{A1.1 Specific Current Water Quality Sampling Technology}

\section{US DH-81}

\subsection{Background and Theory of US DH-81 Depth-Integrating Suspended-Sediment} Samplers

1.1.1 General information

- The US DH-81 is a half-pound hand-held sampler used in shallow wadable streams. This particular model collects the sample by submerging the sampler into the water with the sampler pointing directly into the flow of the stream or river where then the vertical profile of the stream is measured following the EWI or EDI method. The US DH-81 typically consists of a polypropylene cap and plastic (Delrin $®)$ nozzle and a 1 liter perfluoroalkoxy (PFA) sample bottle or bag. The Federal Interagency Sedimentation Project (FISP) does not recommend glass as the receiving container as glass can break easily due to being unprotected with the design on the sampler.

- Information on the UD DH-81 Sampler came from Chapter A2 of the National Field Manual for the Collection of WaterQuality Data and from FISP website: 
http://fisp.wes.army.mil/Instructions\%20US_DH81_010612.pdf.

1.4.2 What data is being analyzed/gathered?

- Depending on the construction materials used, the sampler can collect either organic or inorganic contaminants.

- Suspended sediment.

- Samples are to be analyzed in the lab.

1.4.3 Sample methodology/Data collection

- The sample is collected by submerging the sampler into the flow of the stream or river at desired depth where then water and suspended sediment enter the nozzle and collect into the sampler container. Air is displaced in the container and exits through an air vent hole in the cap of the sampler.

- The sample collected is transferred into a clean compositing vessel, usually a glass carboy or a churn splitter, where aliquots are pulled from the compositing vessel, filtered if necessary, and placed into bottles dictated by the laboratory for the different analyses requested (Hank Johnson, personal communication, June 10, 2011).

1.5 Data Quality Advantages and Issues

- The US DH-81 can take an accurate representative sample of the stream or river with a velocity between 2.0 to 6.2 feet per second (ft. /sec) with a 3/16-in nozzle and 1.5 to $7.6 \mathrm{ft}$. / $/ \mathrm{sec}$ with a 1/4-in nozzle, and 2.0 to $7.0 \mathrm{ft}$. / $/ \mathrm{sec}$ with a 5/16-in nozzle. Anything outside of this range does not allow for an isokinetic sample.

- It is recommended that the volume of sample collected to not exceed $800 \mathrm{~mL}$ when using a $1 \mathrm{~L}$ sample container. If exceeded, isokinetic sampling is no longer obtained.

- Sampling depth should not exceed $15 \mathrm{ft}$.

1.6 General Cost Considerations

1.6.2 Field and laboratory time and material requirements 1.6.2.1 Cost of sampling instrument

- Cost of sampler is unknown, estimated $\sim \$ 200$.

- Contact FISP

1.6.2.2 Cost of storage and transport

- Standard cost for transport of samples USGS labs apply.

1.6.2.3 Cost of sample analysis

- Standard costs for sample analysis apply.

1.6.2.4 Cost of human labor to operate/deploy sample technology

- Human labor will be required to collect sample.

1.7 Advantages and Disadvantages of US DH-81

- Light weight and easy to use.

- Collects a representative sample of stream/river condition.

- Depth limiting due to being hand-held. 


\section{US DH-95}

1.1 Background and Theory of US DH-95 Depth-Integrating Suspended-Sediment Samplers

1.1.1 General information

- The US DH-95 is a hand-held or cable-and-reel suspended sediment sampler used in medium velocity streams or rivers. The sampler weighs 29 pounds and made out of bronze and is plastic dip coated, a commercially available material. The cable-and-reel method is more favored.

- The sampler construction materials are either a $1 \mathrm{~L}$ plastic or a 1 L Teflon container so both organic and inorganic samples can be collected.

- Information on the US DH-95 sampler came from FISP website: http://fisp.wes.army.mil/Instructions\%20US\%20DH95\%20000608.pdf.

1.1.2 What data is being analyzed/gathered?

- Trace elements.

- Suspended sediment.

- Depending on the construction materials used, the sampler can collect either organic or inorganic contaminants.

- Samples are to be analyzed in the lab.

\subsubsection{Sample methodology/Data collection}

- A cable-and-reel method can be used by lowering and raising the sampler into the water at a constant transit rate through the water column. The sampler should be connected to a hanger bar and the hanger bar to a suspension cable due to weight of sampler.

- The sample is collected by submerging sampler into the flow of the stream or river at desired depth where then water and suspended sediment enter the nozzle and collect into the sampler container. Air is displaced in the container and exits through an air vent hole in the cap of the sampler.

- The sample collected is transferred into a clean compositing vessel, usually a glass carboy or a churn splitter, where aliquots are pulled from the compositing vessel, filtered if necessary, and placed into bottles dictated by the laboratory for the different analyses requested (Hank Johnson, personal communication, June 10, 2011).

1.2 Data Quality Advantages and Issues

- The US-DH 95 can take an accurate representative sample of the stream or river with a velocity between 1.7 to $7.4 \mathrm{ft}$. /sec, depending 
on the nozzle diameter in use. Anything outside of this range does not allow for an isokinetic sample.

- It is recommended that the volume of sample collected to not exceed $800 \mathrm{~mL}$ when using a $1 \mathrm{~L}$ sample container. If exceeded, isokinetic sampling is no longer obtained.

- Sampling depth should not exceed 13.3 - $15 \mathrm{ft}$., depending on nozzle size.

1.3 General Cost Considerations

1.3.1 Field and laboratory time and material requirements

1.3.1.1 Cost of sampling instrument

- $\$ 2,556.00$

- Price came from FISP website: http://fisp.wes.army.mil/price_list.htm.

1.3.1.2 Cost of storage and transport

- Standard cost for transport of samples to USGS labs apply.

1.3.1.3 Cost of sample analysis

- Standard costs for sample analysis apply.

1.3.1.4 Cost of human labor to operate/deploy sample technology

- Human labor will be required to collect samples.

1.4 Advantages and Disadvantages of US DH-95

- Collects a representative sample of stream/river condition.

- Due to the weight of the sampler, a hanger bar connected to a suspension cable needs to be used, usually connected on a boat.

\section{US D-95}

1.1 Background and Theory of US D-95 Depth-Integrating Suspended-Sediment Samplers

1.1.1 General information

- The US D-95 is a 64 pound plastic dip coated bronze sampler used for collecting a depth-integrated, flow-weighted suspended sediment sample in medium-velocity streams. The suspension method is cable-and-reel.

- The sample container of the US D-95 is either $1 \mathrm{~L}$ plastic container or a $1 \mathrm{~L}$ Teflon container, thus organics or inorganics can be sampled.

- Information on the US D-95 came from FISP website: http://fisp.wes.army.mil/Instructions\%20US\%20D95\%20000608\%20.pdf.

1.1.2 What data is being analyzed/gathered?

- Depending on the construction materials used, the sampler can collect either organic or inorganic contaminants.

- Suspended sediment.

- Samples are to be analyzed in the lab. 


\subsubsection{Sample methodology/Data collection}

- A cable-and-reel method can be used by lowering and raising the sampler into the water at a constant transit rate through the water column. The sampler should be connected to a hanger bar and the hanger bar to a suspension cable.

- When the sampler is submerged, the water and suspended sediments flow in through the nozzle filling the sample container bag at a rate that is nearly the same as the same as the stream/river velocity. Air is displaced in the container and exits through an air vent hole in the cap of the sampler.

- The sample collected is transferred into a clean compositing vessel, usually a glass carboy or a churn splitter, where aliquots are pulled from the compositing vessel, filtered if necessary, and placed into bottles dictated by the laboratory for the different analyses requested (Hank Johnson, personal communication, June 10, 2011).

1.2 Data Quality Advantages and Issues

- The US D-95 can take an accurate representative sample of the stream or river with a velocity between 1.7 to $6.7 \mathrm{ft}$. /sec, depending on the nozzle diameter in use.

- It is recommended that the volume of sample collected to not exceed $800 \mathrm{~mL}$ when using a $1 \mathrm{~L}$ sample container. If exceeded, isokinetic sampling is no longer obtained.

- Sampling depth should not exceed 13.3 - $15 \mathrm{ft}$., depending on nozzle size.

\subsection{General Cost Considerations}

1.3.1 Field and laboratory time and material requirements

1.3.1.1 Cost of sampling instrument

- $\$ 2,958.00$

- Price came from FISP website: http://fisp.wes.army.mil/price_list.htm.

\subsubsection{Cost of storage and transport}

- Standard cost for transport of sample to USGS labs apply.

1.3.1.3 Cost of sample analysis

- Standard cost for sample analysis applies.

1.3.1.4 Cost of human labor to operate/deploy sample technology

- Human labor will be needed to collect samples.

1.4 Advantages and Disadvantages of US D-95

- Collects a representative sample of stream/river condition.

- Due to the weight of the sampler, a hanger bar connected to a suspension cable needs to be used, usually connected on a boat. 


\section{US D-96}

1.1 Background and Theory of US D-96 Depth-Integrating Suspended-Sediment Samplers

1.1.1 General information

- The US D-96 is a 132 pound depth integrating collapsible bag sampler which can sample up to $3 \mathrm{~L}$ operated by cable and reel. The sampler is made of bronze and aluminum. All metal is plastic dip coated, a commercially available material.

- The sampler container is either a perfluoroalkoxy bag or a polyethylene bag so either organics or inorganics can be sampled for.

- Information on the US D-96 came from FISP website: http://fisp.wes.army.mil/Instructions\%20US\%20D96\%20Instructions\%20020709.pdf.

1.1.2 What data is being analyzed/gathered?

- Depending on the construction materials used, the sampler can collect either organic or inorganic contaminants.

- Suspended sediment.

- Samples are to be analyzed in the lab.

1.1.3 Sample methodology/Data collection

- A cable-and-reel method can be used by lowering and raising the sampler into the water at a constant transit rate through the water column. The sampler should be connected to a hanger bar and the hanger bar to a suspension cable.

- When the sampler is submerged, the water and suspended sediments flow in through the nozzle filling the sample container bag at a rate that is nearly the same as the same as the stream/river velocity. Air is displaced in the container and exits through an air vent hole in the cap of the sampler.

- The sample collected is transferred into a clean compositing vessel, usually a glass carboy or a churn splitter, where aliquots are pulled from the compositing vessel, filtered if necessary, and placed into bottles dictated by the laboratory for the different analyses requested (Hank Johnson, personal communication, June 10, 2011).

\subsection{Data Quality Advantages and Issues}

- The US D-96 can take an accurate representative sample of the stream or river with a velocity between 2 to $12.5 \mathrm{ft}$. /s, depending on nozzle size.

- The sampler has a maximum transit rate (the vertical lowering and raising of the sampler through the water column) of 0.4 times the streams velocity. There is no minimum transit rate, as long as the sampler container volume is not exceeded. 
- The sampler can sample to depths of 39-110 ft., depending on nozzle size.

\subsection{General Cost Considerations}

1.3.2 Field and laboratory time and material requirements

1.3.2.1 Cost of sampling instrument

- $\$ 5,741.00$

- Price came from FISP website:

http://fisp.wes.army.mil/price_list.htm.

\subsubsection{Cost of storage and transport}

- Standard cost for transport of samples to USGS labs apply.

1.3.2.3 Cost of sample analysis

- Standard costs for sample analysis apply.

1.3.2.4 Cost of human labor to operate/deploy sample technology

- Human labor will be required to collect samples.

1.4 Advantages and Disadvantages of US D-96

- Collects a representative sample of stream/river condition.

- Due to the weight of the sampler, a hanger bar connected to a suspension cable needs to be used, usually connected on a boat.

\section{US D-99}

1.1 Background and Theory of US D-99 Depth-Integrating Suspended-Sediment Samplers

1.1.1 General information

- The US D-99 is a 285 pound depth integrating collapsible bag sampler which can use $3 \mathrm{~L}$ or $6 \mathrm{~L}$ sample bags and is operated by a cable-and-reel. The sampler is made of bronze and aluminum where all metal is plastic dip coated, a commercially available material.

- The sampler container is either a perfluoroalkoxy bag or a polyethylenes bag so either organics or inorganics can be sampled for.

- Information on the US D-99 came from FISP website: http://fisp.wes.army.mil/In_Development_US_XD-99.htm.

1.1.2 What data is being analyzed/gathered?

- Depending on the construction materials used, the sampler can collect either organic or inorganic contaminants.

- Suspended sediment.

- Samples are to be analyzed in the lab.

1.1.3 Sample methodology/Data collection

- A cable-and-reel method can be used by lowering and raising the sampler into the water at a constant transit rate through the water column. The sampler should be connected to a hanger bar and the hanger bar to a suspension cable. 
- When the sampler is submerged, the water and suspended sediments flow in through the nozzle filling the sample container bag at a rate that is nearly the same as the same as the stream/river velocity. Air is displaced in the container and exits through an air vent hole in the cap of the sampler.

- The sample collected is transferred into a clean compositing vessel, usually a glass carboy or a churn splitter, where aliquots are pulled from the compositing vessel, filtered if necessary, and placed into bottles dictated by the laboratory for the different analyses requested (Hank Johnson, personal communication, June 10, 2011).

1.2 Data Quality Advantages and Issues

- The US D-99 can take an accurate representative sample of the stream or river with a velocity up to $15 \mathrm{ft}$. /s.

- The sampler can sample to depths of 78-220 ft., depending on nozzle size.

1.3 General Cost Considerations

1.3.2 Field and laboratory time and material requirements

1.3.2.1 Cost of sampling instrument

- Cost of sampler is unknown.

1.3.2.2 Cost of storage and transport

- Standard cost for transport of samples to USGS labs apply.

1.3.2.3 Cost of sample analysis

- Standard costs for sample analysis apply.

1.3.2.4 Cost of human labor to operate/deploy sample technology

- Human labor will be required to collect samples.

1.4 Advantages and Disadvantages of US D-99.

- Collects a representative sample of stream/river condition.

- Due to the weight of the sampler, a hanger bar connected to a suspension cable needs to be used, usually connected on a boat.

\section{B1.0 Evaluation of Emerging Water Quality Technologies.}

- Research has concluded that there are no emerging technologies that could replace isokinetic depth-integrating samplers for analysis of stream/river conditions. 


\section{B2.0 Tables to Compare and Contrast Technologies.}

\section{Table 2-2. Isokinetic depth-integrating water-quality samplers and sampler characteristics}

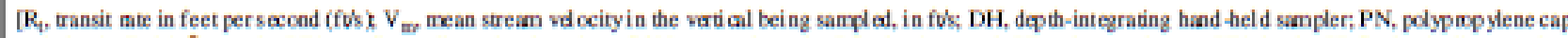

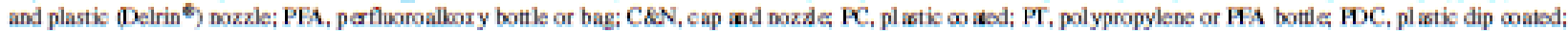
D, depth-integnating samp ler, P, plastic no zzle; TFE, tetrafluoroethylane nozzle]

\begin{tabular}{|c|c|c|c|c|c|c|c|c|c|c|c|}
\hline \multirow{2}{*}{$\begin{array}{l}\text { Sampler } \\
\text { designa- } \\
\text { tion }\end{array}$} & \multirow{2}{*}{$\begin{array}{c}\text { Sampler } \\
\text { construction } \\
\text { material }\end{array}$} & \multicolumn{3}{|c|}{ Sampler dimensio ns } & \multirow{2}{*}{$\begin{array}{c}\text { Dista nee } \\
\text { of nouzle } \\
\text { from } \\
\text { bott om, } \\
\text { in inches }\end{array}$} & \multirow[b]{2}{*}{$\begin{array}{c}\text { Suspension } \\
\text { method }\end{array}$} & \multirow{2}{*}{$\begin{array}{l}\text { Maximum } \\
\text { calibrated } \\
\text { velo city. } \\
\text { in fe et } \\
\text { per } 200 \text { ond }\end{array}$} & \multirow{2}{*}{$\begin{array}{l}\text { Maximum } \\
\text { depth. } \\
\text { in fe et }\end{array}$} & \multirow{2}{*}{$\begin{array}{c}\text { Sampler } \\
\text { cont ainer } \\
\text { size. } \\
\text { in liters }\end{array}$} & \multirow{2}{*}{$\begin{array}{l}\text { Nourb } \\
\text { intake size.' } \\
\text { in inches }\end{array}$} & \multirow{2}{*}{$\begin{array}{l}\text { Max inum } \\
\text { transit rate } \\
\text { ratio, }{ }_{2}^{2} N_{11}\end{array}$} \\
\hline & & $\begin{array}{l}\text { Length } \\
\text { (inch) }\end{array}$ & $\begin{array}{l}\text { Width } \\
\text { (inch) }\end{array}$ & $\begin{array}{l}\text { Wei ght } \\
\text { (pound) }\end{array}$ & & & & & & & \\
\hline US DH 81 & PN or HA-C\&N & 365 & 32 & 30.5 & 44 & $\begin{array}{l}\text { Hand-held } \\
\text { (FC) }\end{array}$ & 7.6 & $\begin{array}{l}15 \\
15 \\
13.3\end{array}$ & $\begin{array}{c}1 \\
(\mathrm{PT})\end{array}$ & $\begin{array}{r}3 / 16 \\
144 \\
1516\end{array}$ & $\begin{array}{r}0.2 \\
3 \\
.4\end{array}$ \\
\hline US DH 95 & $\begin{array}{c}\text { Bnnse }(\mathrm{PDC}) \\
\text { with } \mathrm{PN} \text { or } \\
\text { PFA-C\&N }\end{array}$ & 22 & 66 & 2 & 4.8 & $\begin{array}{c}\text { Hand-held } \\
\text { or reel } \\
\text { and able }\end{array}$ & 7,4 & $\begin{array}{l}15 \\
15 \\
13.3\end{array}$ & $\begin{array}{c}1 \\
\text { (PT) }\end{array}$ & $\begin{array}{r}3 / 16 \\
1 / 4 \\
516\end{array}$ & $\begin{array}{l}.18 \\
.32 \\
4 \\
\end{array}$ \\
\hline US D.95 & $\begin{array}{c}\text { Bronx (HDC) } \\
\text { with PNor } \\
\text { PFA-C\&N }\end{array}$ & 26 & 6.7 & 64 & 48 & $\begin{array}{l}\text { Rexl and } \\
\text { cable }\end{array}$ & 6.7 & $\begin{array}{l}15 \\
15 \\
13.3 \\
\end{array}$ & $\begin{array}{c}1 \\
\text { (PT) }\end{array}$ & $\begin{array}{r}3 / 6 \\
1 / 4 \\
15 / 16\end{array}$ & $\begin{array}{l}.18 \\
.32 \\
.4\end{array}$ \\
\hline US D-96 & $\begin{array}{l}\text { Bmnx (PDC) } \\
\text { with } \mathrm{P} \propto \mathrm{THE} \\
\text { nozzle }\end{array}$ & 35 & 8 & 132 & 4 & $\begin{array}{c}\text { Rexl and } \\
\text { cable }\end{array}$ & 12.5 & $\begin{array}{r}110 \\
60 \\
39\end{array}$ & $\begin{array}{c}3 \\
(\mathrm{HF})\end{array}$ & $\begin{array}{r}3716 \\
14 \\
5716\end{array}$ & $\begin{array}{l}.4 \\
4 \\
.4\end{array}$ \\
\hline US D -99 & $\begin{array}{l}\text { Bmnx (PDC) } \\
\text { with } \mathrm{P} \propto \mathrm{THE} \\
\text { nozzles }\end{array}$ & 47 & 10 & $2 \pi$ & 9.5 & $\begin{array}{l}\text { Rexl and } \\
\text { able }\end{array}$ & 15 & $\begin{array}{r}220 \\
120 \\
78 \\
\end{array}$ & $\begin{array}{c}6 \\
(\mathrm{H} A)\end{array}$ & $\begin{array}{r}3 / 16 \\
1 / 4 \\
516\end{array}$ & $\begin{array}{l}4 \\
4 \\
4\end{array}$ \\
\hline
\end{tabular}

'Nozik stres are thoe recommendad forthe applicaion shown.

2Rda bo NPM 4, Appendix A, for ma rimum tansit-ate anges, and vo Office of Surface Wais Tochnical Memoandum 94 05, datad lanury 31, 1994.

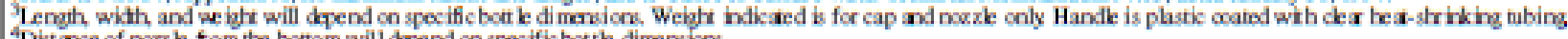

"Dist ance of nove $\mathrm{k}$ fom the bottom will dquend on specific bottle dimensicos.

Table 2-2 comes from page 24 of Chapter A2 of the National Field Manual for the Collection of Water-Quality Data. The table compares and contrasts the five isokinetic samplers as used by USGS.

\section{C1.0 Comparison and conclusion}

\subsection{Comparison}

- There is no emerging technology to compare current isokinetic depthintegrating samplers to.

\subsection{Conclusion}

- It has been concluded that USGS use of the Federal Interagency Sedimentation Project's Isokinetic Depth-Integrating Sampler equipment is the best option in collecting a representative whole water sample from a stream or river for water quality analysis for organic and inorganic analytes. Especially in regards to collecting suspended sediment. 
- Depending on the stream or rivers velocity will determine what model of sampler to use to collect sample.

Chapter Reference:

Lane, S.L., Flanagan, Sarah, and Wilde, F.D., 2003, Selection of equipment for water sampling (ver. 2.0): U.S. Geological Survey Techniques of Water-Resources Investigations, book 9, chap. A2, March, accessed__date_ at http://pubs.water.usgs.gov/twri9A2/.

U.S. Geological Survey, 2006, Collection of water samples (ver. 2.0): U.S. Geological Survey Techniques of Water-Resources Investigations, book 9, chap. A4, September, accessed __date_ at http://pubs.water.usgs.gov/twri9A4/. 


\section{Appendix C}

Portable Autonomous Whole-Water Sampler Pumps Chapter

A1.0 Current Portable Autonomous Whole-Water Sampler Pumps

3.0 Background and Theory of Sampling Method - Portable Autonomous Whole-Water Samplers.

1.0.1 Basic description

- This technology can be used in a variety of water bodies such as lakes, reservoirs, groundwater wells, rivers, and streams. Portable autonomous whole-water samplers are pumps deployed in the environment to sample water quality. These pumps are deployed at location near but out of the water, have a tube go into the water at desired depth, have the sampler mechanically pump water into a collection container according to pre-programmed intervals, by using a vacuum or peristaltic pump system. Autonomous whole-water sampling pumps can perform composite and/or discrete sampling, depending on make and model of pump.

- Information on the specific technology came from various company websites that make portable autonomous whole-water samplers.

1.0.2 How many variations of technology

- Many brands and models of composite and discrete portable autonomous whole-water samplers.

- Other brands that deserve to be mentioned are Aquamatic and SIRCO, made by Southwell Controls. All of which will be mentioned in the specific current water quality sampling technology section.

1.0.3 Types of data obtainable

- Number of parameters depending on construction materials.

A1.1 Specific Current Portable Autonomous Whole-Water Sampler Pumps

\section{Aquacell P2-COMPACT, Aquacell P2-MULTIFORM, \& Aquacell-COOLBOX}

1.1 Background and Theory of Aquacell P2-COMPACT, Aquacell P2-MULTIFORM, \& Aquacell-COOLBOX.

- Aquamatic is a company based out of Manchester, UK that specializes in automatic waste water sampling equipment. 
Aquamatic makes the Aquacell P2-COMPACT, Aquacell P2MULTIFORM, \& Aquacell-COOLBOX.

- Information on Aquamatic's pumps came from Aquamatic's websites: http://www.aquamaticsamplers.com/products.asp \& http://www.aquamaticsamplers.com/images/products/Aquacell $\% 20$ Portable $\% 20$ Range $\% 20+\% 20$ Company $\% 20$ Information $\%$ 20-\%20V06-03.pdf.

1.1.2 What data is being analyzed/gathered

- All three samples collect whole-water samples for water quality analysis.

- Depending on construction materials in contact with the sampler will depend if organic or inorganic anaytes can be sampled. For the three samplers, sample materials are braided PVC or Teflon intake tubes, glass or polypropylene sample containers, and polypropylene or Teflon sample chamber top.

- The autonomous whole-water samplers can be used in any water body.

1.1.3 Sample methodology/Data collection

- Aquacell P2-COMPACT: A composite sampler capable of sampling up to $5 \mathrm{~L}$ in volume. Can take $350+$ composite samples at predetermined intervals.

- Aquacell P2-COOLBOX: A composite sampler capable of sampling up to $5 \mathrm{~L}$ in volume. Can also refrigerate sample up to 5 days and can take $350+$ composite samples at predetermined intervals.

- Aquacell P2-MULTIFORM: A discrete sampler capable of sample options of 12 × $1 \mathrm{~L}, 12$ × $0.75 \mathrm{~L}, 4 \times 5 \mathrm{~L}$, and 4 × $4.5 \mathrm{~L}$ samples at predetermined intervals.

1.2 Data Quality Advantages and Issues

- Capable of collecting a representative whole water sample.

- Discussion of QA/QC: Samples collected in this manner can be tested for accuracy via the use of replicates.

- Sample times can be triggered by time, flow, or by event.

1.3 Field and laboratory time and material requirements

1.3.2.1 Cost of sampling instrument:

- Contact Aquamatic directly.

1.3.2.2 Cost of storage and transport:

- Standard costs for transport of samples to USGS labs apply.

1.3.2.3 Cost of sample analysis:

- Standard costs for sample analysis apply.

1.3.2.4 Cost of human labor to operate/deploy sample technology:

- Human labor will be required to deploy and retrieve the device.

1.4 Advantages and Disadvantages of d Aquacell P2-COMPACT, Aquacell P2MULTIFORM, \& Aquacell-COOLBOX.

- Light weight and easy to use. 
- Large sample quantity for composite samplers and multiple discrete sample options for the MULTIFORM model.

\section{PVS 4100, PVS 4120, \& PVS 4150}

1.1 Background and Theory of PVS 4100, PVS 4120, \& PVS 4150

- $\quad$ The PVS 4100, PVS 4120, \& PVS 4150 are portable autonomous whole-water samplers manufactured by Southwell Controls. Southwell Controls makes these specific pumps for SIRCO.

- Information on the PVS 4100, PVS 4120, \& PVS 4150 came from SIRCO's website: http://www.sircosamplers.com/portable-water-samplers.cfm.

1.1.2 What data is being analyzed/gathered

- All three samples collect whole-water samples for water quality analysis.

- Depending on construction materials in contact with the sampler will depend if organic or inorganic anaytes can be sampled. For the three samplers, sample materials made from either Nylon reinforced PVC or Teflon-lined PVC tubing, and polypropylene or Teflon sample containers.

- The automated whole-water samplers can be used in any water body.

1.1.3 Sample methodology/Data collection

- PVS 4100: A composite and discrete sampler capable of sampling 24 x $0.5 \mathrm{~L}$ and 24 x 1 L Samples. Can take operate up to $168+$ hours and samples can be collected at predetermined time intervals. Samples can be collected up to 250 feet away.

- PVS 4120: A smaller version of the PVS 4100 but can only operate up to 84+ hours and sample from 20 feet away.

- PVS 4150: A composite capable of collecting up to $9 \mathrm{~L}$ of

1.5 Data Quality Advantages and Issues sample, sampling at predetermined intervals.

- Capable of collecting a representative whole-water sample.

- Discussion of QA/QC: Samples collected in this manner can be tested for accuracy via the use of replicates.

1.6 Field and laboratory time and material requirements

1.6.2.1 Cost of sampling instrument:

- Contact Southwell Controls directly.

1.6.2.2 Cost of storage and transport:

- Standard costs for transport of samples to USGS labs apply.

1.6.2.3 Cost of sample analysis:

- Standard costs for sample analysis apply.

1.6.2.4 Cost of human labor to operate/deploy sample technology: 
- Human labor will be required to deploy and retrieve the device.

1.7 Advantages and Disadvantages of the PVS 4100, PVS 4120, \& PVS 4150

- Light weight and easy to use

- Large sample quantity for composite samplers and multiple discrete sample options for the PVS 4100 and the PVS 4120 models.

\section{ISCO 3710, ISCO 6712, \& ISCO 6712 C}

1.1 Background and Theory of ISCO 3710, ISCO 6712, \& ISCO $6712 \mathrm{C}$

- The ISCO 3710, ISCO 6712, \& ISCO $6712 \mathrm{C}$ are portable autonomous whole-water samplers manufactured by Teledyne ISCO.

- Information on the ISCO 3710, ISCO 6712, \& ISCO 6712 C came from Pine Environmental Services, Inc. websites: http://www.pine-environmental.com/composite-samplers/isco3710.htm\#content \& http://www.pineenvironmental.com/composite-samplers/isco-6712.htm\#content \& http://www.pine-environmental.com/compositesamplers/isco-6712-c.htm\#content.

1.7.2 What data is being analyzed/gathered

- All three samples collect whole water samples for water quality analysis.

- Depending on construction materials in contact with the sampler will depend if organic or inorganic anaytes can be sampled. For the three samplers, sample materials are either PVC or Teflon.

- The autonomous whole-water samplers can be used in any water body.

1.1.3 Sample methodology/Data collection

- ISCO 3710: A composite capable of collecting up to 2.5 gallon glass container or a 4 gallon polyethylene bottle up to 24 individual sampling events that can be preset at various time intervals.

- ISCO 6712: Is the same as the ISCO $6712 \mathrm{C}$ but 2 inches larger in diameter (20 inches).

- ISCO 6712 C: A composite and discrete sampler capable of multiple sample bottle arrangement options ranging from $24 \mathrm{x}$ $0.5 \mathrm{~L}$ to $1 \times 5.5 \mathrm{gal}$ and can sample up to roughly 200 feet away. Samples can be taken at predetermined time intervals.

1.8 Data Quality Advantages and Issues

- Capable of collecting a representative whole water sample.

- The ISCO 6712 and ISCO $6712 \mathrm{C}$ can also be submerged in water while operating. 
- Discussion of QA/QC: Samples collected in this manner can be tested for accuracy via the use of replicates.

1.9 Field and laboratory time and material requirements

1.9.2.1 Cost of sampling instrument:

- Contact ISCO directly.

1 9.2.2 Cost of storage and transport:

- Standard costs for transport of samples to USGS labs apply.

1.9.2.3 Cost of sample analysis:

- Standard costs for sample analysis apply.

1.9.2.4 Cost of human labor to operate/deploy sample technology:

- Human labor will be required to deploy and retrieve the device. 1.10 Advantages and Disadvantages of the ISCO 3710, ISCO 6712, \& ISCO 6712C

- Light weight and easy to use.

- ISCO 6712 and ISCO 6712C can be submerged allowing for a deeper and wider range of sample capability meeting the demands of various sampling events.

- Large sample quantity for composite samplers and multiple discrete sample options for the ISCO 6712 model.

\section{B1.0 Emerging Portable Autonomous Whole-Water Sampler Pumps}

- Research has concluded that there are no emerging technologies that could replace current portable automated whole-water samplers. According to Kirk P. Smith of USGS, most of the technological improvements to the portable sampler design over the past 10-15 years have involved various options of sample bottle sizes and number of sample bottles for discrete sampling (personal communication, April 11, 2011). Other than these advances, the portable water samplers have not evolved much.

\section{C1.0 Comparison and conclusion}

1.0 Comparison

- There is no emerging technology to compare current portable autonomous whole-water sampler pumps to.

1.1 Conclusion

- Recommendations as to what technologies should be adopted by the Survey. 
- It is difficult to determine what brand and models USGS use as USGS does not endorse a specific product line or source, according to Stanley C. Skrobialowski of USGS (personal communication, April 4, 2011). However, it is recommended that USGS investigate further the use of the Aquacell P2-MULTIFORM, Aquacell P2-COOLBOX, SIRCO's PVS 4100 and the PVS 4120, and the ISCO 6712 and ISCO 6712C automatic pumps. The recommendation for the Aquacell P2MULTIFORM is due to its capability to take up to $12 \times 0.75 \mathrm{~L}$ separate samples. Smaller sample volumes are ideal for remote locations as water is heavy in weight and can be difficult to transport. Aquacell P2-COOLBOX is an attractive choice if sample preservation is an issue as this sampler is capable of self-refrigeration if desired. The PVS 4100 and the PVS 4120 are attractive samplers as they are capable of both composite and discrete samples. The ISCO 6712 and ISCO $6712 \mathrm{C}$ are recommended for further investigation as these automatic pumps can be submerged in water if desired and have refrigeration capability through the use of ice. Sampling for nitrogen and phosphorus species with automatic samplers with the lack of preservation for several days can significantly change the concentrations in a representative sample. The use of these samplers can cut labor cost due to their capability of being in the field for long durations and being the most resent pump technology, ultimately preventing failure of operation in the field. These are the latest models in portable autonomous whole-water sample pumps. 


\section{Appendix D}

Autonomous Submergible Whole-Water Samplers Chapter

A1.0 Current Autonomous Submergible Whole Water Samplers

2 Background and Theory of Sampling Method of Autonomous Submergible Whole-Water Samplers. 1.0.1 Basic description

- Autonomous submergible whole-water samplers can be programed to take samples automatically at various time intervals while completely submerged in a water body at a desired depth. Samplers collect a sample of water that is representative of the water body's current condition.

- The technology mentioned below is typically applied and used in the ocean meeting the demands of harsh environments. However, many of these ocean whole-water sampler technologies have the potential to be applied to lake and river environments.

- The sampler is deployed and automatically collects samples according to pre-programmed intervals. Typically, the samplers are time-series samplers capable of collecting several individual samples and can be fitted with a variety of filters and stabilizing solutions. The samplers mentioned can be deployed for a few hours or up to several months, depending on the sampling interval desired. During deployment, the unit can record data including sample collection timing, flow rate, volume, and even real time data.

- The main mechanical components of each sampler includes a watertight pressure-resistant housing, a pump assembly, a multi-port valve, and sample containers. The sampler can be anchored to an ocean, lake, river bed or tethered to a surface vessel. Most samplers have locations on them to attach additional sensors while deployed in the field.

- Information on the specific technology came from various company or research laboratory websites.

1.0.2 How many variations of technology

- McLane Labs make a number of versions of these samplers ranging in maximum operation depth, samples collected, and sampling volumes.

- Remote Access Sampler (RAS-100 \& RAS-500)

- Environmental Process Sampler (ESP)

- Phytoplankton Sampler (PPS)

- Zooplankton Sampler (ZPS)

- Large Volume Pump (WTS-LV) 
- General Oceanics makes the M1018S Series Syringe Sampler Rosette ${ }^{\circledR}$.

- KC Denmark makes a twelve $50 \mathrm{~mL}$ syringe sampler.

\subsubsection{Types of data obtainable}

- Whole-water samples for various water quality analysis dependent on sampler design.

A1.1 Specific Current Autonomous Submergible Whole-Water Samplers

\section{RAS-100 \& RAS-500}

1.1 Background and Theory of Remote Access Sampler (RAS)-100 \& RAS-500

1.1.1 General information

- McLane Labs from Falmouth, MA makes the Remote Access

Sampler (RAS) in 100 and $500 \mathrm{ml}$ sample collection volumes, called the RAS-100 and RAS-500.

- The RAS samplers can be used up to 6,000 meters in depth for multiple time series sampling.

- Sampling unit is advertised for deep oceanic studies.

- Information on the RAS-100 \& RAS-500 came from McLane Labs websites:

http://www.mclanelabs.com/sites/default/files/sub_page_files/McLa ne\%20RAS-100\%20Data\%20Sheet-WEB.pdf \&

http://www.mclanelabs.com/sites/default/files/sub_page_files/McLa ne-RAS-500-Datasheet.pdf.

2.1.2 What data is being analyzed/gathered?

- Ambient water quality data and suspended material.

- Biological information.

- Dissolved nutrients.

- Trace metals.

- Dissolved organic carbon.

- Materials that come in contact with sample are metalized polyethylene lined or Tedlar sample bags. The multiport valve is made from HYDROX plastic or Kynar plastic.

1.1.3 Sample Methodology

- The sample is collected via a peristaltic pump at a predetermined interval.

- Additional probes can be mounted onto the unit, with their data and the sample collection data downloaded after the unit is retrieved. 
- The RAS-100 collects 48 different $100 \mathrm{~mL}$ samples while the RAS500 collects 48 different $500 \mathrm{~mL}$ samples.

2.2 Data Quality Advantages and Issues

- This device collects samples from the ocean or lake floor or from a specific depth when tethered to a surface vessel. Depth profiles are not typically done with these devices due to the depth of the bodies of water. Thus, these devices can only report on the quality of water from their deployed depth.

- Samples collected in this manner can be tested for accuracy via the use of replicates to maintain quality control.

\subsection{General Cost Considerations}

2.3.2 Field and laboratory time and material requirements

2.3.2.1 Cost of sampling instrument

- Contact McLane Labs directly.

\subsubsection{Cost of storage and transport}

- Standard costs for transport of samples to USGS labs apply.

2.3.2.3 Cost of sample analysis

- Standard costs for sample analysis apply.

\subsubsection{Cost of human labor to operate/deploy sample technology}

- Human labor will be required to deploy and retrieve the device.

2.4 Advantages and Disadvantages of RAS- $100 \& 500$

- The advantages are the ability to collect samples under extreme depth and pressure, with a large number of replicates collected in a regimented time series.

- The disadvantages of this technology include the lack of depth profile, as this device is stationary typically sitting on the floor of the body of water it is sampling. Additionally, the great depths at which samples are collected make device retrieval potentially hazardous.

- Not utilized in freshwater systems.

\section{Environmental Process Sampler}

\subsection{Background and Theory of Environmental Process Sampler (EPS)}

\subsubsection{General information}

- McLane Labs from Falmouth, MA makes the Environmental Process Sampler (EPS) which is designed for collection and analysis of water quality in ocean environments up to $50 \mathrm{~m}$ in depth to determine microorganisms and their gene product.

- Information on the EPS came from McLane Labs websites: http://www.mbari.org/education/internship/05interns/05papers/Kfull er.pdf \& http://www.mclanelabs.com/master_page/producttype/samplers/environmental-sample-processor. 
2.4.2 What data is being analyzed/gathered?

- Discrete water samples of concentrated microorganisms and particles for the in-situ analysis of gene product of microorganisms.

- Remotely retrieve and analyze data in real time.

\subsubsection{Sample Methodology}

- EPS can identify taxa of microorganism by using sandwich hybridization chemistry and nucleic acid probes to identify target taxa.

- Can be deployed in the environment up to three months.

- EPS can transmit real-time data of hybridization assays.

- Can also collect water samples for parallel analysis.

1.2 Data Quality Advantages and Issues

- The devise can be deployed up to three months unattended while transmitting real-time data.

- Not advertised for freshwater environments but could be applied.

- Discussion of QA/QC: Samples collected in this manner can be tested for accuracy via the use of replicates.

1.3 General Cost Considerations

1.3.1 Field and laboratory time and material requirements

1.3.1.1 Cost of sampling instrument:

- Contact McLane Labs directly

1.3.1.2 Cost of storage and transport:

- Standard costs for transport of samples to USGS labs apply.

1.3.1.3 Cost of sample analysis:

- Standard costs for sample analysis apply.

1.3.1.4 Cost of human labor to operate/deploy sample technology:

- Human labor will be required to deploy and retrieve the device.

1.4 Advantages and Disadvantages of the EPS

- The advantages are the ability to collect samples under extreme depth and pressure, with a large number of replicates collected in a regimented time-series.

- The EPS is not advertised for fresh water environments but no limitations to freshwater environments are seen.

\section{Phytoplankton Sampler}

1.1 Background and Theory of Phytoplankton Sampler (PPS)

\subsubsection{General information}

- McLane Labs from Falmouth, MA makes the Phytoplankton Sampler (PPS) which is designed for automatic collection 
particulates onto a membrane filter in ocean environments up to $5,500 \mathrm{~m}$ in depth.

- Information on the PPS came from McLane Labs websites: http://www.mclanelabs.com/sites/default/files/sub_page_files/PPS\% 20Manual\%20Rev\%20B-WEB.pdf \& http://www.mclanelabs.com/master_page/producttype/samplers/phytoplankton-sampler.

2.4.3 What data is being analyzed/gathered?

- Phytoplankton

- Trace metals

- Suspended particles

\subsubsection{Sample Methodology}

- Data gathered consist of particulates that are filtered through a 47 mm filter.

- Twenty-four discrete samples can be collected

- Maximum volume filtered is $10 \mathrm{~L}$ per filter

1.5 Data Quality Advantages and Issues

- The devise can be deployed up to 14 months unattended while transmitting real-time data.

- Not advertised for freshwater environments but could be applied.

- Discussion of QA/QC: Samples collected in this manner can be tested for accuracy via the use of replicates.

\subsection{General Cost Considerations}

1.6.1 Field and laboratory time and material requirements

1.6.1.1 Cost of sampling instrument:

- Contact McLane Labs directly.

1.6.1.2 Cost of storage and transport:

- Standard costs for transport of samples to USGS labs apply.

1.6.1.3 Cost of sample analysis:

- Standard costs for sample analysis apply.

1.6.1.4 Cost of human labor to operate/deploy sample technology:

- Human labor will be required to deploy and retrieve the device.

1.7 Advantages and Disadvantages of PPS

- Not utilized in freshwater systems.

- The PPS is not yet utilized in fresh water environments but nothing states that it cannot be used in fresh water.

\section{Zooplankton Sampler}

1.1 Background and Theory of Zooplankton Sampler (ZPS)

\subsubsection{General information}


- McLane Labs from Falmouth, MA makes the Zooplankton Sampler (ZPS) which is designed for in-situ automatic collection of zooplankton. Sampling is done with a flexible predetermined timeseries sampling schedule based on experiments needs.

- Information on the ZPS came from McLane Labs websites: http://www.mclanelabs.com/sites/default/files/sub_page_files/McLa ne-ZPS-Datasheet.pdf \& http://www.mclanelabs.com/master_page/producttype/samplers/zooplankton-sampler.

2.4.4 What data is being analyzed/gathered?

- Zooplankton

\subsubsection{Sample Methodology}

- 50 individual zooplankton samples can be collected.

- Samples are collected and preserved on mesh collection belt.

- Other belt materials can be aluminum foil or urethane.

- Samples can be observed on the mesh belt or in the lab.

1.2 Data Quality Advantages and Issues

- The devise can be deployed up to 12 months depending on pumping rates.

- Can be used up to 5,000 meters in depth.

- Not advertised for freshwater environments but could be applied.

- Discussion of QA/QC: Samples collected in this manner can be tested for accuracy via the use of replicates.

\subsection{General Cost Considerations}

1.3.1 Field and laboratory time and material requirements

1.3.1.1 Cost of sampling instrument:

- Contact McLane Labs directly.

1.3.1.2 Cost of storage and transport:

- Standard costs for transport of samples to USGS labs apply.

1.3.1.3 Cost of sample analysis:

- Standard costs for sample analysis apply.

1.3.1.4 Cost of human labor to operate/deploy sample technology:

- Human labor will be required to deploy and retrieve the device.

1.4 Advantages and Disadvantages of ZPS

- The ZPS is not advertised for fresh water environments but nothing states that it cannot be used in fresh water.

\section{Large Volume Pump (WTS-LV)}

1.1 Background and Theory of Large Volume Pump (WTS-LV)

\subsubsection{General information}


- McLane Labs from Falmouth, MA makes the Large Volume Pump (WTS-LV) which is designed for a single event in-situ automatic collection of suspended and dissolved particulates onto a Black Acetal $142 \mathrm{~mm}$ membrane filter.

- Information on the WTS-LV came from McLane Labs websites: http://www.mclanelabs.com/sites/default/files/sub_page_files/McLa ne-WTS-LV-Datasheet.pdf \& http://www.mclanelabs.com/master_page/producttype/samplers/wts-lv-large-volume-pump.

1.4.1 What data is being analyzed/gathered?

- Suspended and dissolved particulates

- Chlorophyll

- Trace metals

- Phytoplankton

1.1.3 Sample Methodology

- A single event sample filters $X$ volumes of water through a membrane filter at slow rates to not destroy sample.

- Samples can be observed on the membrane filter in the lab.

1.2 Data Quality Advantages and Issues

- The devise is deployed to measure a single sampling event.

- Can be used up to 5,000 meters in depth.

- Depending on membrane filter size a range of 2,500 - 15,000 L can be filtered.

- Not advertised for freshwater environments but could be applied.

- Discussion of QA/QC: Samples collected in this manner can be tested for accuracy via the use of replicates.

\subsection{General Cost Considerations}

1.3.1 Field and laboratory time and material requirements

1.3.1.0 Cost of sampling instrument:

- Contact McLane Labs directly.

1.3.1.1 Cost of storage and transport:

- Standard costs for transport of samples to USGS labs apply.

1.3.1.2 Cost of sample analysis:

- Standard costs for sample analysis apply.

1.3.1.3 Cost of human labor to operate/deploy sample technology:

- Human labor will be required to deploy and retrieve the device.

1.4 Advantages and Disadvantages of WTS-LV

- The WTS-LV allows for multiple pump size and filter porosity to allow for a range of sample collection.

- Only can be used for a single event. 


\section{Model M1018S Series Syringe Sampler Rosette ${ }^{\circledR}$}

1.1 Background and Theory of M1018S

1.1.1 General information

- General Oceanics from Miami, FL makes the M1018S Series

Syringe Sampler Rosette ${ }^{\circledR}$ which is a multiple bottle sampling array designed to take water samples at any depth using 12-24 individual $10 \mathrm{cc}$ or $60 \mathrm{cc}$ glass or disposable syringes. General Oceanics makes a number of multiple bottle sampling arrays to meet various sample volume demands. The M1018S is the smallest sample size array.

- Information on the M1018S Series Syringe Sampler Rosette ${ }^{\circledR}$ came from General Oceanics website:

http://www.generaloceanics.com/product.php?productid=1172\&cat= 40\&page $=1 \#$ tabs.

1.4.2 What data is being analyzed/gathered?

- Whole water sample for water quality analysis.

- Depending on material of the syringes will determine if organic or inorganic analytes can be measured. Syringe materials compatible with the sampler are glass, polypropylene, or Teflon.

\subsubsection{Sample Methodology}

- 12-24 individual glass or disposable syringes

- Syringes range from 10-60 cc in volume.

- A conducting cable is attached to the sampler telling the sampler to take a sample or it can be programed to take samples at a predetermined time interval.

1.5 Data Quality Advantages and Issues

- Can take samples at any depth.

- Not advertised for freshwater environments but could be applied.

- Sensors can be attached to the sampler is desired.

- Discussion of QA/QC: Samples collected in this manner can be tested for accuracy via the use of replicates.

1.6 General Cost Considerations

1.6.1 Field and laboratory time and material requirements

1.3.1.0 Cost of sampling instrument:

- $\$ 20,760.00$

1.6.1.1 Cost of storage and transport:

- Standard costs for transport of samples to USGS labs apply.

1.6.1.2 Cost of sample analysis:

- Standard costs for sample analysis apply.

1.6.1.3 Cost of human labor to operate/deploy sample technology:

- Human labor will be required to deploy and retrieve the device. 


\subsection{Advantages and Disadvantages of M1018S}

- Samples can be collected at any depth (maximum depth is unknown).

- Can be programed to take samples at predetermined intervals unattended.

- Can be mounted on an anchor at various depths in a water body.

- Small enough for a one person to deploy sampler.

- Breier, J.A. et. al. attached a rosette multi-sampler to a remotely operated vehicle for vertical-profiling.

\section{Volt DC Motor Driven Multiple Water Station with 12 pcs 50 ml Syringes}

\subsection{Background and Theory of 24 Volt DC Motor Driven Multiple Water Station with 12 pcs $50 \mathrm{ml}$} Syringes

\subsubsection{General information}

- KC Denmark from Silkeborg, Denmark makes the 24 Volt DC Motor Driven Multiple Water Station with 12 pcs 50 ml Syringes, which is a multiple bottle sampling array designed to take water samples at any depth using 12 individual $50 \mathrm{~mL}$ nylon PA 6.6 syringes.

- Information on 24 Volt DC Motor Driven Multiple Water Station with 12 pcs $50 \mathrm{ml}$ Syringes came from KC Denmark's website: http://www.kc-denmark.dk/public_html/Watersamplers/sampler.htm.

1.4.3 What data is being analyzed/gathered?

- Whole water sample for water quality analysis.

\subsubsection{Sample Methodology}

- 12 individual $50 \mathrm{~mL}$ nylon PA 6.6 syringes. Syringes can also be constructed from polypropylene or Teflon so organic and inorganic analytes can be sampled.

- A conducting cable is attached to the sampler telling the sampler to take a sample or it can be programed to take samples at a predetermined time interval.

1.8 Data Quality Advantages and Issues

- Can take samples at any depth (maximum depth is unknown).

- Not advertised for freshwater environments but could be applied.

- Sensors can be attached to the sampler is desired.

- Can sample up to 6,000 meters in depth.

- Discussion of QA/QC: Samples collected in this manner can be tested for accuracy via the use of replicates.

\subsection{General Cost Considerations}

1.9.1 Field and laboratory time and material requirements 1.3.1.0 Cost of sampling instrument: 
- Contact KC Denmark directly.

1.9.1.1 Cost of storage and transport:

- Standard costs for transport of samples to USGS labs apply.

1.9.1.2 Cost of sample analysis:

- Standard costs for sample analysis apply.

1.9.1.3 Cost of human labor to operate/deploy sample technology:

- Human labor will be required to deploy and retrieve the device.

1.10 Advantages and Disadvantages of 24 Volt DC Motor Driven Multiple Water Station with 12 pcs $50 \mathrm{ml}$ Syringes Sampler

- Samples can be collected at any depth up to 6,000 m.

- Can be programed to take samples at predetermined intervals unattended.

- Small enough where no mechanics are needed to lower and raise the sampler.

- Can be attached to a remotely operated vehicle.

B1.0 Evaluation of Emerging Submerged, Automatic Whole Water Sample Technologies

\section{Boat Including Automated Water Sampling Device and Method of Using the Same}

\subsection{Background/Theory}

- The Boat Including Automated Water Sampling is an invention created by Carl J. Lange and is found in the United States Patent Application Publication US2010/0095789 A1 on April 22, 2010. The website:

http://www.google.com/patents?id=CJTOAAAAEBAJ\&printsec=abstract\&zoom $=4 \# \mathrm{v}=0$ nepage $\& \mathrm{q} \& \mathrm{f}=$ false.

- The invention is a small boat that is remotely operated from shore by a multi-channel radio control unit and is powered by a solar hydrogen electrochemical reactor.

- The sampler in the patent is designed to take up to four discrete samples in glass test tubes but can be manipulated for increase number of sample containers.

- The boat can be operated on any water body.

- Boat operator can control movement of boat and sampling from the multi-channel radio control unit.

1.1 Method of Sampling \& QA/QC

- Attached to the boat is a sampling device designed for a plurality of sampling tubes that can be programed to take a multiple samples at a variety of depth and latitudes. The sampler is attached to a robotic winch that lowers and raises the sampler.

- Sampling tubes are attached to a disk which can rotate around a second disk, which holds on an aperture that allows water flow for sampling.

- The sampler in the patent is designed to take up to 4 samples in glass test tubes. 
- For QA/QC, replicates of samples collected can be obtained.

1.4 Field and laboratory time and material requirements

1.4.1 Cost of sampling instrument

- Cost of boat and sampler is unknown

1.4.2 Cost of storage and transport

- Standard costs for transport of samples USGS labs apply.

1.4.3 Cost of sample analysis

- Standard costs for sample analysis apply.

1.4.4 Cost of human labor to operate/deploy sample technology

- Human labor will be required to deploy, operate, and retrieve the sampler.

1.5 Advantages and disadvantages of this specific technology

- Sample container is located on the bottom of the boat, thus, allowing sampling in heavily contaminated water that could be harmful to field technicians.

- The sampler design can be manipulated to increase the amount of samples.

- Sampler can be lowered to any desired depth.

\section{Bed Water Sampling Device}

\subsection{Background/Theory}

- The Bed Water Sampling Device is an invention created by Eberhard J. Sauter assignee of Stiftung Alfred-Wegener-Institut (AWI) Fuer Polar-und Meeresforschung from Bremerhaven, Denmark. The device is found in United States Patent US7,757,573 B2 from July 20, 2010. The website:

http://www.google.com/patents?id=1zDSAAAAEBAJ\&printsec=abstract\&zoom=4\&sou rce $=$ gbs_overview_r $\&$ cad $=0 \# \mathrm{v}=$ onepage $\& \mathrm{q} \& \mathrm{f}=\mathrm{false}$. On the AWI website a description of the bed sampler can be found at:

http://www.awi.de/en/research/research_divisions/geosciences/marine_geochemistry/equi pment/bottom_water_sampler/.

- The Bed Water Sampling Device is an improved bed water sampling device to capture a more accurate representative sample of bed water. Bed water is the transitional zone between sediments and the water directly above it.

- The Bed Water Sampling Device can be used in all water environments.

1.1 Method of Sampling \& QA/QC

- The Bed Water Sampling Device consist of multiple horizontal sample containers at different heights from the water bed that can rotate to align directly with the water flow, allowing free flow of water through the sample container until sample is collected. The sample is collected by sealing the open ends of the container simultaneously to capture a representative sample of the bed water.

- Samples are collected with a time-controlled release.

- The sampler is anchored to the water bed. 
- For QA/QC, replicates of samples collected can be obtained.

1.2 Field and laboratory time and material requirements

1.5.1 Cost of sampling instrument

- Cost of boat and sampler is unknown

1.5.2 Cost of storage and transport

- Standard costs for transport of samples to USGS labs apply.

1.5.3 Cost of sample analysis

- Standard cost for sample analysis apply

1.5.4 Cost of human labor to operate/deploy sample technology

- Human labor will be required to deploy and retrieve the sampler.

1.3 Advantages and disadvantages of this specific technology

- When compared to other bed water samplers, this sampler is the only sampler that freely rotates in the water column to align up with the direction of water flow.

- This bed water sampler uses a design that captures the water sample by closing both sides as opposed to a suction mechanism, usually piston filled, which could prevent an accurate representative sample.

C1.0 Comparison and conclusion

\subsection{Comparison}

- Compare and contrast between current vs. emerging

- Comparison of the current and emerging technologies is difficult as each sampler has its own specific purpose for water quality assessment. Thus, the following is comments on the overall effectiveness of the technologies mentioned previously.

- Accuracy/precision: The McLane Labs technology is precise and accurate equipment along with General Oceanics and KC Denmark. The emerging technology was only found in US Patents thus accuracy and precision have not been fully studied.

- Ease of deployment and operation: All of McLane Labs equipment appears to be on the larger size and may need several people to aid in deployment and retrieval, not to mention the need of a boat. General Oceanics and KC Denmark appear to be smaller and can be deployed and retrieved by a single person. The operation of the autonomous samplers can be completed by any personal trained in the programing of the time-interval sampling computer technology.

- Efficiency: Autonomous submergible whole-water samplers reduce man hours in collecting samples as these samplers can be left unattended while operating up to several months in the field, depending on sampling intervals.

- Cost-benefit analysis: This technology is relatively expensive but could reduce cost if deployed in remote sites due to cost of travel to sites.

1.1 Conclusion

- Recommendations as to what technologies should be adopted by the Survey 
- Research on current and emerging autonomous submergible whole-water samplers has concluded that most of the technology lies in oceanic research; however, this technology can be applied to freshwater whole-water sampling events for the benefit of USGS.

- For USGS purposes of freshwater whole-water sampling, McLane Labs equipment could be used in freshwater environments for various water quality analyses. Even though McLane Labs equipment is advertised for ocean use, some of the equipment, such as the RAS-100 and RAS-500, can be incorporated into USGS freshwater whole-water sampling of rivers and lakes. The RAS series is capable of collecting up to 48 different individual samples. The RAS models can be deployed in the field in a lake, reservoir, or large river for up to a year unattended collecting discrete water samples at any desired interval. Deployment up to a year can greatly reduce labor cost as visits to a site will be reduced and quality of data will be enhanced as the RAS models can stay in one place, undisturbed at one location, and can sample from the sample location for some predetermined interval. This method of sampling can give accurate seasonal change for a variety of environmental parameter.

- General Oceanic's M1018S Sampler Rosette ${ }^{\circledR}$ and KC Denmark's 24 Volt DC Motor Driven Multiple Water Station would be a great choice of sampler when smaller volumes of sample are needed. The M1018S can sample from 12 to 24 individual samples ranging from 10-60 mL in volume while the KC Denmark sampler can sample 12 individual $50 \mathrm{~mL}$ sample. Smaller sample volumes would be preferred when in remote locations when having to hike in and out heavy field equipment.

- For emerging whole-water sampling technology, it is recommended that USGS looks into the two emerging technologies mentioned. The Boat Including Automated Water Sampling Device and Method of Using the Same invention, invented by Carl J. Lang, is a sampler that be operated from shore. This sample method can be favored when sampling in lakes and rivers that are too polluted for human contact or difficult to access by boat. The Bed Water Sampling Device invention, invented by Eberhard J. Sauter, may be of interest to USGS for bed water sampling. Sauter's invention claims to be the first bed water samplers that can freely rotate in the water column for optimal representative sampling. This sampler can be applied to lake or large river research.

\section{Literature Cited}

Brier, J.A. et. al., 2009. A suspended-particle rosette multi-sampler for discrete biogeochemical sampling in low-particle-density waters. Deep-Sea Research I. 56: 1579-1589. 